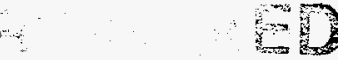 \\ Mag 221900 \\ OSTI
}

\section{A Comparision Of TRUEX \\ And CMP Solvent Extraction \\ Processes For Actinide Removal \\ From ICPP Wastes}
R. S. Herbst
K. N. Brewer
T. G. Garn
J. D. Law
R. T. Tillotson
T. A. Todd

\section{zㄴockheed \\ Idaho Technologies Company}




\section{DISCLAMMER}

Portions of this document may be illegible in electronic image products. Images are produced from the best available original document. 


$$
\text { NEL-96/0094 }
$$

\title{
A COMPARISION OF TRUEX AND CMP SOLVENT EXTRACTION PROCESSES FOR ACTINIDE REMOVAL FROM ICPP WASTES
}

\author{
R. S. HERBST \\ K. N. BREWER \\ T. G. GARN \\ J. D. LAW \\ R. T. TILLOTSON \\ T. A. TODD
}

Published April 1996

\begin{abstract}
Idaho National Engineering Laboratory
Waste Management Technologies

Lockheed Idaho Technologies Company

Idaho Falls, Idaho 83415
\end{abstract}

Prepared for the

U. S. Department of Energy

Assistant Secretary for Environmental Management

Under DOE Idaho Operations Office

Contract DE-AC07-94ID13223 



\begin{abstract}
The Idaho Chemical Processing Plant (ICPP) is currently engaged in development efforts for the decontamination of high-level radioactive wastes generated from decades of nuclear fuel reprocessing. These wastes include several types of calcine, generated by high temperature solidification of reprocessing raffinates. In addition to calcine, there are smaller quantities of secondary wastes from decontamination and solvent wash activities which are typically referred to as sodium-bearing waste (SBW). Solvent extraction technologies based on octyl(phenyl)$\mathrm{N}, \mathrm{N}$-diisobutyl-carbamoylmethylphosphine oxide (CMPO, the active extractant in the TRUEX process) and dihexyl-N,N-diethylcarbamoylmethylphosphonate (DHDECMP, the active extractant in the CMP process) are being evaluated for actinide partitioning from these waste streams. Calcines must first be dissolved in an appropriate acidic solution prior to treatment in solvent extraction based processes. The SBW is currently stored as an acidic solution and readily amenable to liquid extraction techniques.

Development efforts to date have revolved around defining and refining baseline flowsheets with the TRUEX and CMP processes for each waste stream. Another objective of this work was to determine which of these technologies are best suited for the treatment of ICPP wastes. Laboratory batch contacts were performed to identify relevant chemistry and distribution coefficients. This information was then used to establish baseline flowsheet configuration with regard to chemistry. The laboratory data were used to model the behavior of the actinides and other constituents in the wastes in countercurrent, continuous processes based on centrifugal contactor technology. The laboratory data and modelling results form the basis for comparison of the two processes.
\end{abstract}

Treatment of the SBW to achieve required actinide decontamination goals is possible with both the CMP and TRUEX processes. The TRUEX process has a slight advantage since it is technically the most mature, CMPO is commercially available, and the TRUEX process typically possesses more pronounced extraction behavior than the CMP process.

Both processes can be used to achieve the necessary actinide decontamination of dissolved calcines. The treatment of dissolved $\mathrm{Zr}$ calcine types indicates some technical drawbacks with the TRUEX process, predominantly associated with the extraction of $\mathrm{Zr}$ to the point the solvent becomes loaded and suppresses extraction of the actinides. It is currently believed that these technical problems can be alleviated and that the TRUEX process will be better suited to calcine treatment based on technical maturity and commercial availability of CMPO. If the problems associated with $\mathrm{Zr}$ extraction by the TRUEX solvent cannot be resolved in the immediate future, the CMP process provides an excellent alternative for the development of an appropriate actinide separations flowsheet. 



\section{ACKNOWLEDGEMENTS}

The technical assistance of A. L. Olson was instrumental in directing the course of this study and in identifying the key aspects of flowsheet development and comparison. The contributions of A. M. Rodriguez were also greatly appreciated.

The authors gratefully acknowledge the support of the Analytical Chemistry Department at the Idaho Chemical Processing Plant. T. J. Tranter, M. L. Evans, I. D. Goodwin, L. R. Hinckley, and B. J. Storms of the Radiochemical Analysis Group efficiently expedited the numerous radionuclide analyses required in support of this work. J. S. Laug and D. S. Lundholm of the Spectrochemical Analysis Group also provided a great deal of support for the analysis of the non-radioactive matrix components. Without the support of these individuals, this study would not have been possible.

\section{DISCLAIMER}

This report was prepared as an account of work sponsored by an agency of the United States Government. Neither the United States Government nor any agency thereof, nor any of their employees, makes any warranty, express or implied, or assumes any legal liability or responsibility for the accuracy, completeness, or usefulness of any information, apparatus, product, or process disclosed, or represents that its use would not infringe privately owned rights. Reference herein to any specific commercial product, process, or service by trade name, trademark, manufacturer, or otherwise does not necessarily constitute or imply its endorsement, recommendation, or favoring by the United States Government or any agency thereof. The views and opinions of authors expressed herein do not necessarily state or reflect those of the United States Government or any agency thereof. 



\section{TABLE OF CONTENTS}

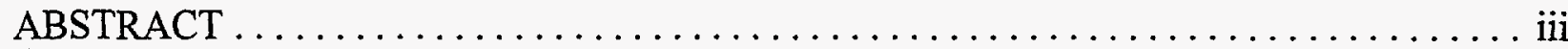

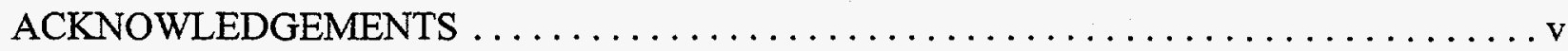

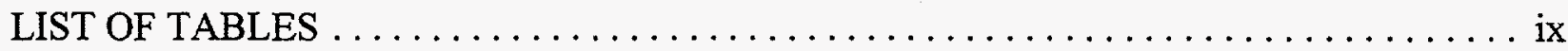

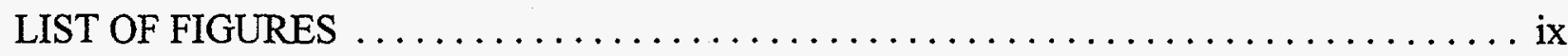

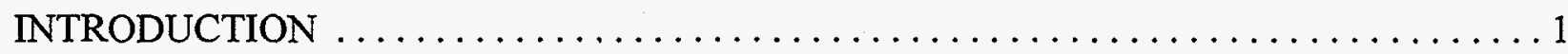

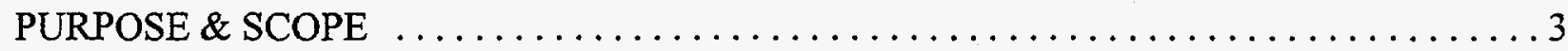

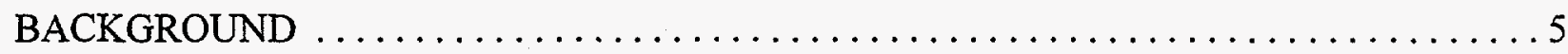

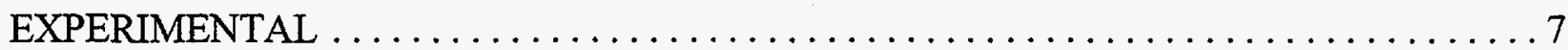

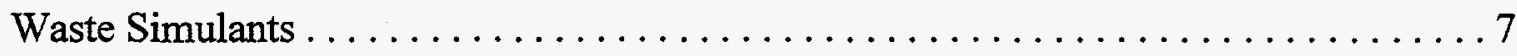

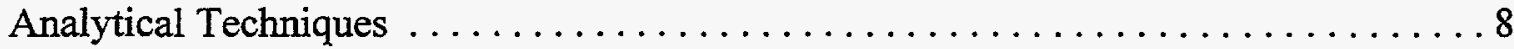

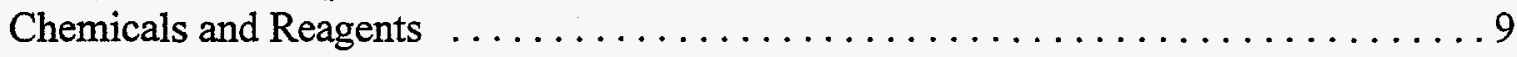

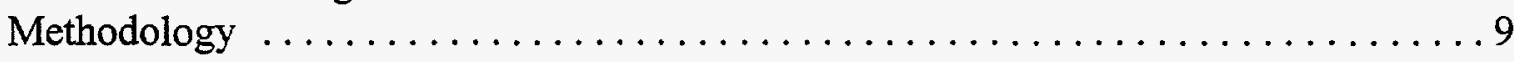

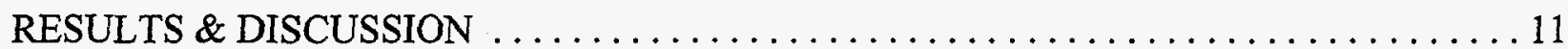

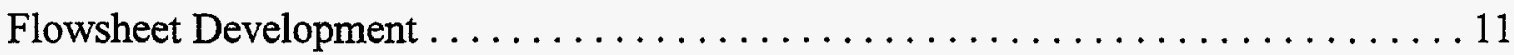

Matrix Components ...................................... 14

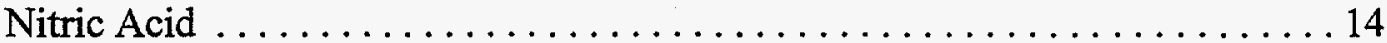

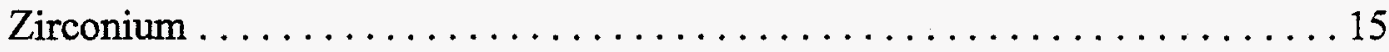

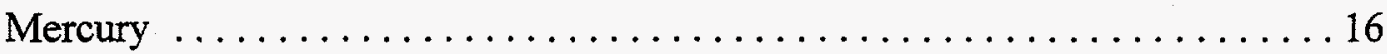

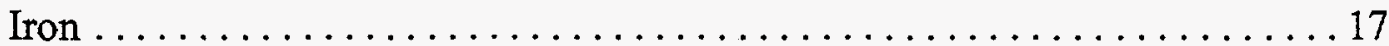

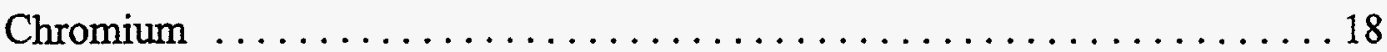

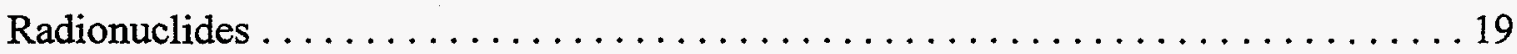

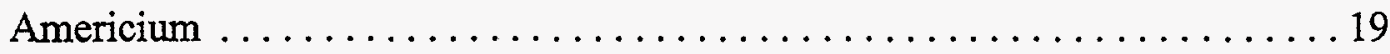

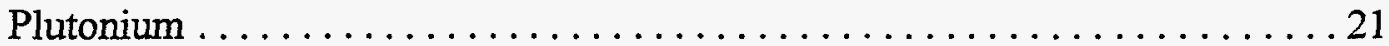

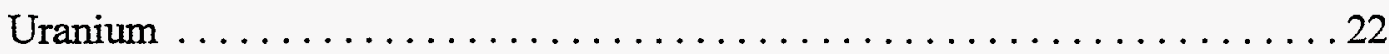

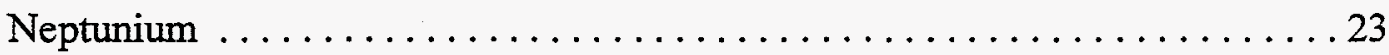

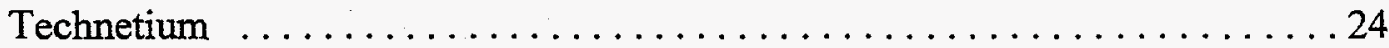

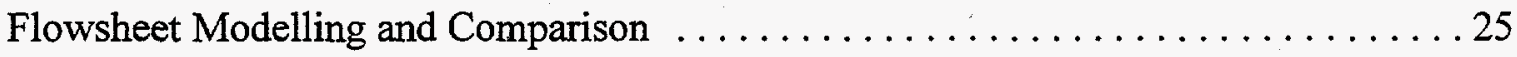

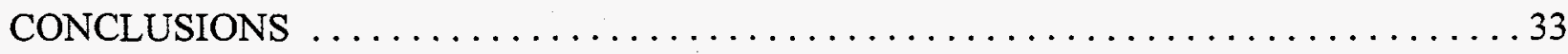

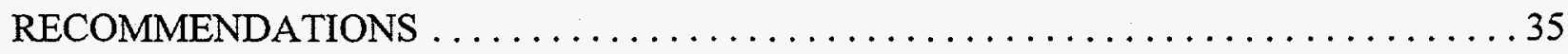

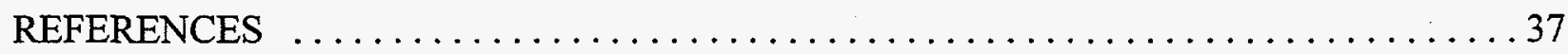





\section{LIST OF TABLES}

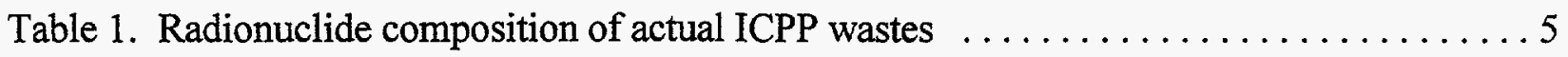

Table 2. Composition of matrix components in waste simulants $\ldots \ldots \ldots \ldots \ldots \ldots \ldots$

Table 3. Radioactive isotopes and analysis methods used as tracers in waste simulants . . . . 8

Table 4. Summary of experimental attempts to define the baseline flowsheets . . . . . . . 12

Table 5. Comparison of $\mathrm{Zr}$ distributions $\left(\mathrm{D}_{\mathrm{zr}}\right)$ for simulated wastes using

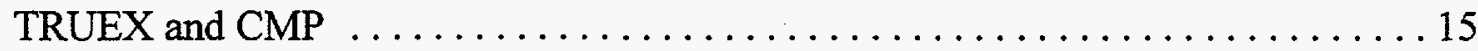

Table 6. Comparison of $\mathrm{Hg}$ distributions $\left(\mathrm{D}_{\mathrm{Hg}}\right.$ ) for simulated SBW with TRUEX and CMP . . 17

Table 7. Comparison of $\mathrm{Cr}$ distributions $\left(\mathrm{D}_{\mathrm{C}}\right)$ for reduced and unreduced Run \#74 calcine . . 19

Table 8. Comparison of Am distributions $\left(\mathrm{D}_{\mathrm{Am}}\right)$ for simulated wastes using

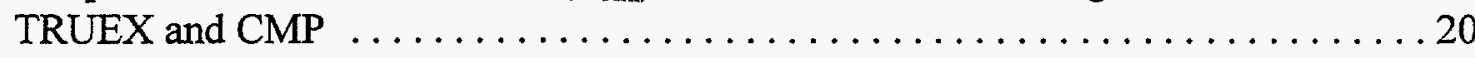

Table 9. Comparison of $\mathrm{P}_{\mathrm{U}}$ distributions $\left(\mathrm{D}_{\mathrm{Pu}}\right)$ for simulated wastes using

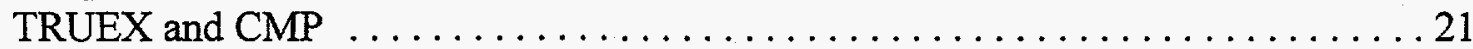

Table 10. Comparison of $U$ distributions $\left(D_{U}\right)$ for simulated wastes using TRUEX

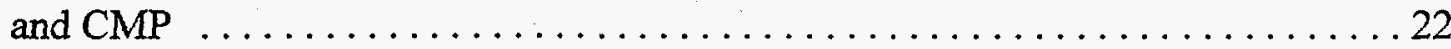

Table 11. Comparison of $\mathrm{Np}$ distributions $\left(\mathrm{D}_{\mathrm{Np}}\right.$ ) for simulated wastes using TRUEX

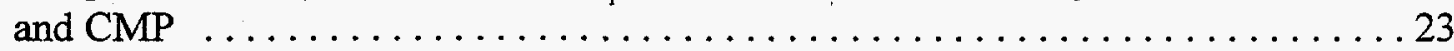

Table 12. Comparison of $\mathrm{Tc}$ distributions $\left(\mathrm{D}_{\mathrm{Tc}}\right)$ for simulated wastes using

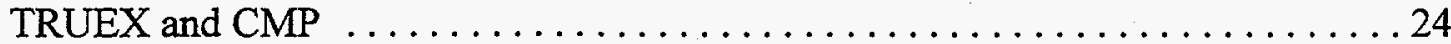

\section{LIST OF FIGURES}

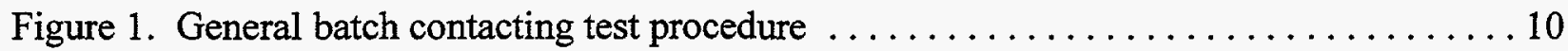

Figure 2. Comparison of nitric acid extraction by the TRUEX and CMP solvents . . . . . . 14

Figure 3. TRUEX flowsheet for the treatment of ICPP sodium-bearing waste $\ldots \ldots \ldots \ldots 27$

Figure 4. CMP flowsheet for the treatment of ICPP sodium-bearing waste $\ldots \ldots \ldots \ldots \ldots 28$

Figure 5. TRUEX flowsheet for the treatment of ICPP dissolved zirconium calcine . . . . . . 29

Figure 6. CMP flowsheet for the treatment of ICPP dissolved zirconium calcine . . . . . . . 30 


\section{INTRODUCTION}

The Idaho Chemical Processing Plant (ICPP), located at the Idaho National Engineering Laboratory, formerly reprocessed spent nuclear fuel to recover uranium. Fuel elements were completely dissolved with nitric and hydrofluoric acids in the headend process. Uranium was recovered from the acidic dissolver product in sequential PUREX/REDOX type processes. After uranium recovery, the liquid raffinates were temporarily stored and ultimately calcined into a solid, granular material. Various calcine types were generated over the years as a result of reprocessing three basic types of fuels: aluminum, stainless steel, and Zircaloy ${ }^{\oplus}$. The resulting calcines are characterized according to the raffinate type, or blends thereof, from which they were produced. The calcine is stored in a series of six individual bin sets, each consisting of large stainless steel vessels encased in concrete vaults. The current inventory of calcine is approximately $4000 \mathrm{~m}^{3}[1]$.

Cleanup of the organic solvent and equipment decontamination was performed with solutions typically high in sodium. This secondary liquid waste, or sodium-bearing waste (SBW), is temporarily stored in the tank farm. The SBW cannot be calcined directly due to bed agglomeration associated with sodium nitrate. Historically, SBW was blended with first cycle raffinates and calcined. Spent fuel reprocessing was halted as of 1992 and the reprocessing raffinates were subsequently calcined, eliminating the blending option to deplete SBW inventories. Currently, there are 5.6 million liters of SBW stored in tanks at the ICPP.

The United States Environmental Protection Agency and the Idaho Department of Health and Welfare filed a Notice of Noncompliance in 1992 contending some of the underground waste storage tanks do not meet secondary containment requirements as set forth in Title 40, Part 265.13 of the Code of Federal Regulations. Consequently, the Department of Energy has agreed to remove SBW from some of the storage tanks by the year 2009 , and from the remaining tanks by 2015 [2].

Several technologies are currently being evaluated for the treatment and final disposition of SBW inventories [2,3]. These technologies include blending with nonradioactive chemicals, essentially diluting sodium, and calcination of the liquid; radionuclide partitioning and immobilization of the resulting high activity (HAW) and low activity (LAW) waste streams; and, numerous pretreatment options to remove sodium, concentrate the liquid, or remove nitrate followed by direct calcination. A peer review for the separations group identified the most prominent technologies for evaluation in early 1993 [3]. Two prominate liquid-liquid extraction processes were targeted as the primary candidates for actinide removal from ICPP wastes as a result of this peer review.

A major emphasis at the ICPP has been directed toward evaluating actinide removal from dissolved calcine solutions and SBW through the evaluation of the TRans Uranic EXtraction (TRUEX) process developed by Horwitz and Schulz [4]. The active extractant used in the TRUEX process solvent is octyl(phenyl)-N,N-diisobutylcarbamoylmethylphosphine oxide 
(CMPO). Tributylphosphate (TBP) is added to the solvent as a phase modifier, to prevent third phase formation, with a paraffinic hydrocarbon used as the diluent. The process has been effectively demonstrated to remove actinides from acidic simulants and actual wastes to well below the $10 \mathrm{nCi} / \mathrm{g} \mathrm{NRC} \mathrm{Class} \mathrm{A} \mathrm{low-level} \mathrm{transuranic} \mathrm{waste} \mathrm{requirements.} \mathrm{Typical} \mathrm{solvent}$ extraction tests have used batch contacts or small-scale continuous countercurrent extractions to evaluate the efficiency of the TRUEX process. Large scale application, as of yet, has not been realized. However, the TRUEX process has received the attention of virtually every country with nuclear processing capabilities.

An equally important endeavor has been the parallel evaluation of the actinide extraction process based on dihexyl-N,N-diethylcarbamoylmethylphosphonate (DHDECMP or simply CMP) as applicable to ICPP wastes. First synthesized by Sidall in the 1960's [5], CMP was the forerunner to the development of CMPO and the TRUEX process. Although chemically similar, CMP generally exhibits lower extraction constants than CMPO and higher concentrations of CMP are required in the organic phase to achieve necessary levels of extraction. The CMP process has not been studied as extensively as the TRUEX process; furthermore, much of the early CMP work was conducted with diluents, such as xylene and diisopropyl benzene, which are unacceptable under current safety criteria [6-8]. Recent work indicates paraffinic hydrocarbons, such as dodecane, are acceptable diluents provided TBP is added to the solvent as a phase modifier $[9,10]$.

Solvent extraction has been widely used in the nuclear reprocessing industry with large scale applications relying primarily on extraction columns. Recent flowsheet development efforts have evolved around the use of centrifugal contactors, which potentially offer several advantages over pulsed columns. Individual contactors function near the efficiency of a theoretical stage. Steady state operation is also acheived quite rapidly in centrifugal contactors. Furthermore, solvent inventories are dramatically reduced in centrifugal contactor based flowsheets, offering a significant economic incentive for relatively expensive extractants such as CMPO. Actinides are removed from the waste by the organic solvent in the extraction section and the aqueous raffinate must be suitably decontaminated to meet NRC Class A LLW requirements for the actinides. Co-extracted matrix components are selectively back extracted from the organic in the scrub section and returned to the extraction section by recombination of the aqueous scrub solution with the feed. The actinides are then removed from the scrubbed organic in the stripping section and the aqueous strip product is appropriately processed and disposed of as the HAW fraction. Finally, the stripped organic is treated in solvent cleanup and re-acidification sections prior to being recycled back to the extraction section.

This report summarizes the efforts to date in the development of baseline actinide separations flowsheets for both types (dissolved calcine and SBW) of ICPP wastes using the TRUEX and CMP processes. It is imperative to realize that such development activities have historically been evolutionary and subject to alteration as the body of knowledge is expanded; therefore, the conclusions drawn in this report are subject to future modifications. 


\section{PURPOSE \& SCOPE}

Ongoing efforts to define a suitable system for partitioning of the actinides from ICPP wastes have identified two viable solvent extraction systems which are potentially capable of obtaining the desired decontamination goals. The TRUEX and CMP processes both appear capable of meeting these objectives. The purpose of this report is to present the results currently available for comparison of the CMP and TRUEX extraction systems. This comparison is designed to indicate applicability of these systems, compared in their best light, for baseline flowsheet development regarding treatment of ICPP wastes. This work will shape the future of continuing development efforts and allow initial conclusions to be drawn regarding which extraction system is "best" for application to ICPP wastes.

General considerations involved in the selection of a suitable solvent extraction system includes (but is not limited to):

1) Extracted species and the extent of extraction are important: What species are extracted and to what extent? There is little need to consider processes which are incapable of partitioning and concentrating the necessary constituents from the waste. A knowledge of distribution coefficients for selected matrix metals and the actinides provides a convenient basis of comparison in this regard.

2) Flowsheet simplicity: Can co-extracted materials be scrubbed from the solvent? Is a scrub section necessary to remove acid prior to actinide re-extraction? Are adjustments to the HLW feed streams required to optimize system performance? Will a single strip section provide gross actinide re-extraction, or are multiple strip sections required?

3) Extraction efficiency is important with regards to equipment costs: What number of "sections" and how many stages are required per section to achieve the necessary decontamination factors? Will multiple cycles of extraction be required to achieve the desired decontamination?

4) Waste minimization: For a given feed volume, what are the respective volumes of the HLW and LLW fractions? Due to the high costs typically associated with the treatment and disposal of these streams, this is potentially the most important criteria with respect to flowsheet selection.

5) Solvent cost and availability: There is little potential to implement a process if the extractant is unavailable in sufficient quantities or is extremely expensive.

6) Technical maturity: The time frame required to develop and implement a process must be within the requirements of having a facility built and operational.

The scope of this work is to simply define and compare baseline process flowsheets based on currently available data. This comparison is useful in determining if the extraction systems are viable and how well they work. Ultimately, any decision regarding process flowsheet selection must rely on suitable economic evaluations. A detailed knowledge of the process requirements will eventually make this task much easier. 



\section{BACKGROUND}

Development activities to date have primarily focused on the use of simulated wastes and batch contacts to define necessary parameters for flowsheet development. Flowsheets developed in this manner are then tested in continuous, countercurrent mode in the $5.5 \mathrm{~cm}$ Centrifugal Contactor Pilot Plant at the ICPP using nonradioactive waste simulants spiked with neodymium or europium as Am surrogates. In the case of the TRUEX process, limited batch experiments have been conducted with actual wastes to verify behavior observed with the waste surrogates. Ultimately, the process flowsheets will be tested on actual waste samples in the $2 \mathrm{~cm}$ Centrifugal Contactor Pilot Plant which was assembled in the Remote Analytical Laboratory hot cell at the ICPP in January 1996.

Compositions of the actual waste solutions will vary dramatically. This is particularly true for the bulk matrix components in the various calcines, depending on the production history of the different calcination campaigns. Consequently, it is advantageous for a separation technology to be suitably robust to work well with the compendium of ICPP wastes.

Although the compositions of the matrix components will vary dramatically with the different waste streams, the radionuclide compositions will be reasonably similar. Recent analytical data for the radionuclides in a sample taken from one of the SBW storage tanks [11] and for a solution of dissolved calcine [12] are listed in Table 1. These data are expected to be reasonably representative of typical SBW and calcine feed streams.

Table 1. Radionuclide composition of actual ICPP wastes.

\begin{tabular}{||l|c|c|c||}
\hline \multicolumn{1}{|c|}{ Element } & Units & SBW [11] & Dissolved Calcine [12] \\
\hline \hline Gross $\alpha$ & $\mathrm{dps} / \mathrm{ml}$ & $3.14 \mathrm{e}+04$ & $5.25 \mathrm{e}+04$ \\
\hline Gross $\beta$ & $\mathrm{dps} / \mathrm{ml}$ & $1.61 \mathrm{e}+07$ & $\mathrm{ND}$ \\
\hline Am-241 & $\mathrm{dps} / \mathrm{ml}$ & $2.92 \mathrm{e}+03$ & $4.61 \mathrm{e}+03$ \\
\hline Pu-238 & $\mathrm{dps} / \mathrm{ml}$ & $1.99 \mathrm{e}+04$ & $4.83 \mathrm{e}+04$ \\
\hline Pu-239 & $\mathrm{dps} / \mathrm{ml}$ & $2.41 \mathrm{e}+03$ & $1.86 \mathrm{e}+03$ \\
\hline Np-237 & $\mathrm{dps} / \mathrm{ml}$ & $1.45 \mathrm{e}+02$ & 20.1 \\
\hline $\mathrm{U}$ & $\mathrm{g} /$ & 0.107 & 0.00269 \\
\hline Cs-134 & $\mathrm{dps} / \mathrm{ml}$ & $1.04 \mathrm{e}+04$ & $\mathrm{ND}$ \\
\hline Cs-137 & $\mathrm{dps} / \mathrm{ml}$ & $4.23 \mathrm{e}+06$ & $8.48 \mathrm{e}+06$ \\
\hline Sr-90 & $\mathrm{dps} / \mathrm{ml}$ & $4.44 \mathrm{e}+06$ & $1.07 \mathrm{e}+07$ \\
\hline Tc-99 & $\mathrm{dps} / \mathrm{ml}$ & $1.41 \mathrm{e}+03$ & 975 \\
\hline Eu-154 & $\mathrm{dps} / \mathrm{ml}$ & $1.62 \mathrm{e}+04$ & $\mathrm{ND}$ \\
\hline
\end{tabular}

$\mathrm{ND}=$ Not Determined 
In the case of calcine feeds, it is important to note that the solid calcine must first be converted to a liquid in a headend process. It is anticipated that the solid calcine will be dissolved in nitric acid, clarified, and used as feed to the separation plant. Some work has been conducted at the ICPP with respect to calcine dissolution $[13,14]$. It is anticipated that a $5 \underline{\mathrm{M}}$ $\mathrm{HNO}_{3}$ solution can be used at a ratio of $1 \mathrm{~kg}$ calcine $/ 10 \mathrm{~L}$ acid for the dissolution.

A second consideration, apparent from the data in Table 1 , is the necessity to remove fission products, particularly $\mathrm{Cs}$ and $\mathrm{Sr}$, from the wastes in order to achieve the necessary radionuclide decontamination. The processes investigated for the purposes of this report are ineffective for $\mathrm{Cs}$ and $\mathrm{Sr}$ removal. A separations plant would therefore incorporate unit operations geared specifically to the removal of these radionuclides. Several technologies including SREX (StRontium EXtraction), cobalt dicarbollide (Russian developed technology for the simultaneous removal of $\mathrm{Sr}$ and $\mathrm{Cs}$ ), and numerous ion exchange methods for Cs removal are being considered for fission product separations. Future efforts will be required to identify specific technologies for and determine the order of the various unit operations. 


\section{EXPERIMENTAL}

\section{Waste Simulants}

Development activities to date have focused on the use of simulated wastes and batch contacts to define necessary parameters for flowsheet development. The compositions of the major matrix constituents in the SBW and dissolved $\mathrm{Zr}$ calcine simulants used in this study are listed in Table 2. Preparation of the SBW simulant was based on analytical data and process knowledge of the current inventory of ICPP SBW. Typical SBW compositions vary slightly between the different tanks and the simulant was prepared to represent the average compositions of various matrix components for all such wastes. The calcine simulant was prepared by dissolution of non-radioactive material produced in the $10 \mathrm{~cm}$ Calciner Pilot Plant (designated Run \#74 calcine) according to procedures established in previous studies [13,14]. Run \#74 calcine was selected as a representative surrogate for typical ICPP zirconium calcine.

Table 2. Composition of matrix components in waste simulants.

\begin{tabular}{|c|c|c|c|}
\hline Element & Units & SBW Simulant & R74 Pilot Plant Calcine \\
\hline Acid & $\underline{N}$ & 1.35 & 3.45 \\
\hline Aluminum & $\underline{\mathrm{M}}$ & 0.548 & 0.49 \\
\hline Boron & $\underline{\mathrm{M}}$ & 0.016 & 0.086 \\
\hline Cadmium & $\underline{\mathrm{M}}$ & 0.002 & ND \\
\hline Calcium & $\underline{\mathrm{M}}$ & 0.044 & 0.78 \\
\hline Chloride & $\underline{\mathrm{M}}$ & 0.022 & ND \\
\hline Chromium & $\underline{M}$ & 0.006 & ND \\
\hline Fluoride & $\underline{M}$ & 0.071 & 1.24 \\
\hline Iron & $\underline{\mathrm{M}}$ & 0.025 & 0.01 \\
\hline Mercury & $\underline{\mathrm{M}}$ & 0.002 & ND \\
\hline Nitrate & $\underline{\mathrm{M}}$ & 4.49 & 6.39 \\
\hline Potassium & $\underline{\mathrm{M}}$ & 0.14 & $\mathrm{ND}$ \\
\hline Sodium & $\underline{\mathrm{M}}$ & 1.25 & 0.012 \\
\hline Sulfate & $\underline{\mathrm{M}}$ & 0.038 & ND \\
\hline Zirconium & $\underline{M}$ & 0.0005 & 0.225 \\
\hline
\end{tabular}

ND $=$ Not Determined 


\section{Analytical Techniques}

The distribution behavior of the various elements studied during these experiments was established by addition (spiking) of radioactive tracers into the waste simulants. Minimal quantities were added to negate impacts of simulant dilution; yet the tracers were added in sufficient quantity to insure detectable levels of radioactivity. The radioactive tracers were taken from available stock solutions or obtained from vendors and prepared to desired specifications by the Radiochemistry Laboratory. Once the tracers were spiked into the respective feed surrogate, a minimum of 24 hours elapsed before the actual tests was performed to insure that the traced species had ample time to equilibrate with the feed matrix. This helped insure that the species added to the feed reached chemical and potentiometric equilibrium and thereby exist in the state as expected in actual waste solutions. The use of radionuclides in evaluation of batch distribution ratios allows direct analysis of both the organic and aqueous phases by either Liquid Scintillation Counting (LSC) for $\alpha-\beta$ emitting isotopes or Gamma Scan Analysis ( $\gamma$-scan) for nuclides undergoing $\gamma$-decay. The specific isotopes and analysis methods used in this study are listed in Table 3. Analytical methods for certain matrix metals, primarily $\mathrm{Cr}$, were typically performed by Inductively Coupled Plasma-Atomic Emission Spectroscopy (ICP-AES) when radioactive tracers were unavailable as surrogates for the non-radioactive species.

Acid concentrations were determined in both organic and aqueous phases by titration with standardized $\mathrm{NaOH}$ to a phenothalein endpoint. Titrations for a given phase containing relatively high metal concentrations (such as the aqueous feeds) were conducted by using a pretitrated solution of potassium oxalate to prevent metal hydrolysis and masking of the phenothalein endpoint. The titration of organic samples was performed by addition of a small aliquot of the organic $(0.1$ to $1 \mathrm{~mL})$ to an excess of water or oxalate ( $220 \mathrm{~mL}$ ) and allowing vigorous mixing for several minutes prior to titration with $\mathrm{NaOH}$.

Table 3. Radioactive isotopes and analysis methods used as tracers in waste simulants.

\begin{tabular}{|c|c|c|c||}
\hline Isotope & Analysis Method & Isotope & Analysis Method \\
\hline Americium-241 & LSC or $\gamma$-scan & Neptunium-239 & LSC \\
\hline Plutonium-238 & LSC & Technetium-99m & LSC \\
\hline Plutonium-239 & LSC & Mercury-203 & $\gamma$-scan \\
\hline Uranium-233 & LSC & Zirconium-95 & $\gamma$-scan \\
\hline
\end{tabular}




\section{Chemicals and Reagents}

All reagent and solution preparations were performed by the ICPP Quality Control (QC) Laboratory using, when possible, available chemicals. Typically, solutions were prepared from chemicals with a minimum of "reagent grade" purity.

CMPO was obtained from Elf Autochem with a reported purity of $>97 \%$ and was used without further purification. The composition of the TRUEX solvent was $0.2 \mathrm{M}$ CMPO, 1.4 M TBP ( $99 \%$, Fluka Ag) in Isopar L ${ }^{\otimes}$ (Exxon). The freshly prepared solvent was washed with sodium carbonate solution, followed by a water wash and finally filtered through Whatman paper as a clean up procedure. The washed TRUEX solvent was then tested for purity by evaluation of Am distributions at different $\mathrm{HNO}_{3}$ concentrations in accord with previous studies $[15,16]$.

Although CMP was formerly produced by Occidental Chemical Company, it is no longer available commercially from any known source. The CMP used in this work was generously donated by Sandia National Laboratory. The purity and previous history of this material is unknown. The composition of the CMP solvent used in this work was $0.5 \underline{\mathrm{M}} \mathrm{CMP}$ and $1.0 \underline{\mathrm{M}}$ TBP ( $\sim 99 \%$, Flukas Ag) in Isopar $L^{\circledR}$ (Exxon) and the solvent was prepared by the ICPP QC Laboratory. Although the effects of CMP purity and composition on Am extraction is undefined, the freshly prepared solvent was treated by the same wash and Am extraction procedure used for the TRUEX solvent $[15,16]$. Pretreatment by this procedure was simply to provide a measure of consistency between different batches of the CMP solvent.

\section{Methodology}

Batch contacts between organic and aqueous solutions were used in all experiments. Contacts were always performed at an organic-to-aqueous phase ratio of unity $(O / A=1)$. The primary data obtained were the distribution coefficient, $D$, defined as:

$$
\mathrm{D}_{\mathrm{X}}=\frac{[\mathrm{X}]_{\text {Org. }}}{[\mathrm{X}]_{\text {Aq. }}}
$$

where $[X]_{\text {Org. }}$ is the equilibrium concentration of species $X$ in the organic phase and $[X]_{A q}$ is the corresponding concentration of $\mathrm{X}$ in the aqueous phase. All contacts were performed by vortex mixing for $\geq 1$ minute and phase disengagement was conducted by high speed centrifugation.

Each organic phase was pre-equilibrated three consecutive times with the respective feed solution which did not contain the species of interest. Pre-equilibration insured the organic was loaded with all extractable matrix components such that the only species being transferred between phases was the one of interest. 
The various flowsheet tests were performed by contacting pre-equilibrated organic with a fresh feed solution in three consecutive contacts labeled E1, E2, and E3. These contacts were used to determine representative species distribution coefficients in the extraction section of a process flowsheet. The loaded organic from the third extraction contact was then contacted three consecutive times with fresh volumes of the appropriate scrub solution. The scrubbed organic was then stripped in three consecutive contacts with fresh strip solution. In some cases, depending on the element being studied, the stripped organic was contacted with a solvent wash solution in several contacts using fresh wash. This manner of conducting batch equilibrium measurements is shown schematically in Figure 1. Using the methodology described, it is possible to evaluate the distribution coefficients which may be anticipated in a countercurrent process. This information was then used to model the anticipated behavior of pertinent components in the different feeds and define the baseline flowsheets.

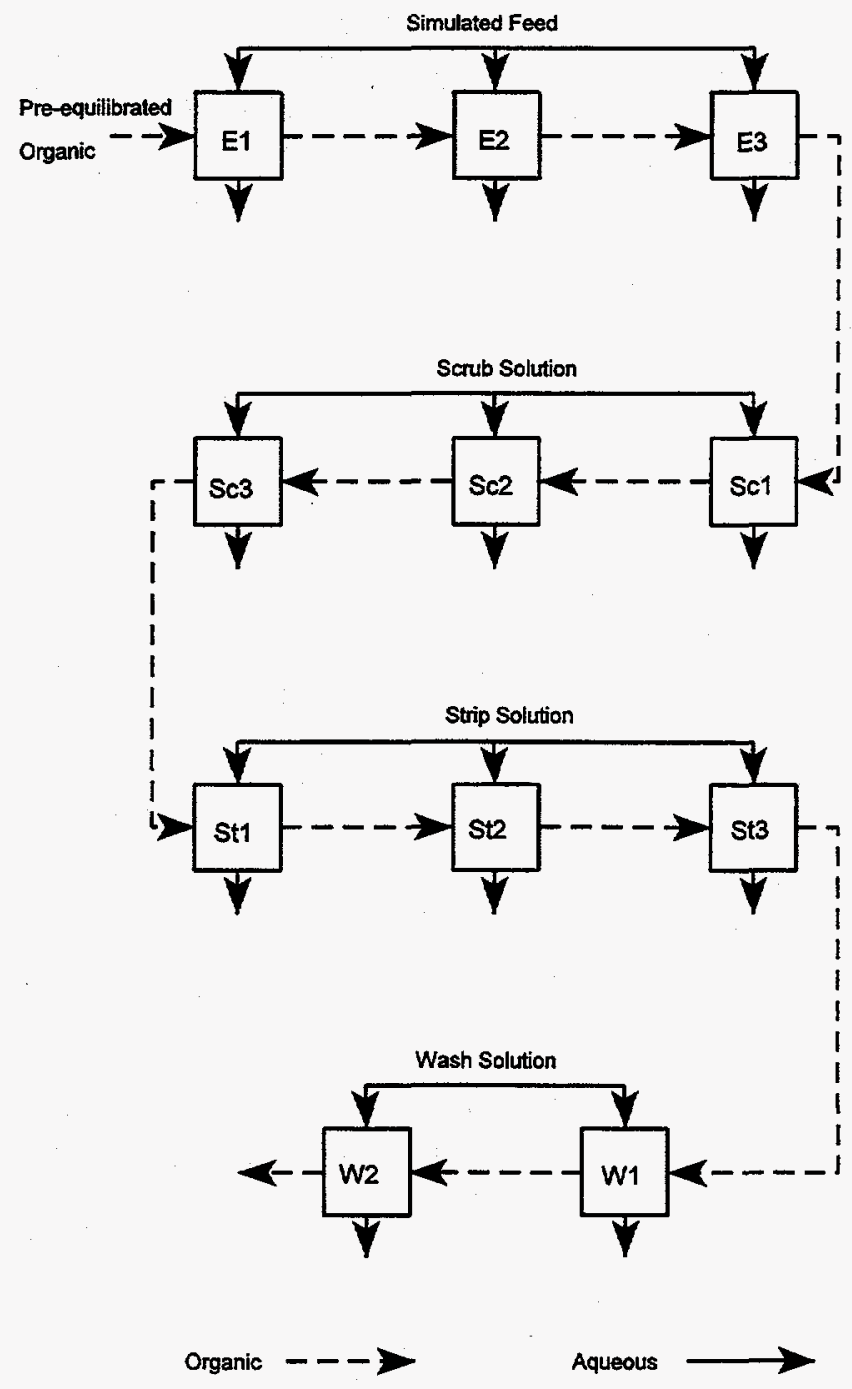

Figure 1. General batch contacting test procedure. 


\section{RESULTS \& DISCUSSION}

\section{Flowsheet Development}

Baseline flowsheets were derived and tested in the laboratory using batch contacts. Such testing was used to define the behavior of the solvents with regard to precipitation and third phase formation (physical behavior) as well as determine the appropriate distribution coefficients to define the behavior of key species during the various processing steps. For the sake of simplicity, distribution data are presented in subsequent sections only for the identified baseline flowsheets. A large amount of data has been collected at the ICPP to define the baseline flowsheets $[11,12,17,18,20-26]$. Many aspects, including numerous scrub and strip reagents were tested for both solvents with both feeds. The use of certain chemicals was often eliminated due to physical problems or inappropriate distributions in scrub or strip contacts. Attempts to define the baseline flowsheets and currently preferred methods are summarized in Table 4 .

Very early experiments with the TRUEX solvent prepared with n-dodecane as the diluent resulted in third phase formation (a second organic phase) when the solvent was contacted with dissolved calcine solutions. To alleviate this problem, the diluent was changed to Isopar $\mathrm{L}^{\circledR}$, a synthetic mixture of branched chain aliphatic hydrocarbons. The elimination of third phase formation by changing the diluent is attributed to increased solubility of the metal-extractant complexes in the branched chain hydrocarbon. Early work based on americium extraction by CMPO indicated there was no measurable differences in distribution coefficients based on the choice of diluent. Consequently, Isopar $\mathrm{L}^{\otimes}$ was selected as the diluent with both extractants in subsequent experiments.

In the case of dissolved calcine feeds, extraction of $\mathrm{Cr}(\mathrm{VI})$, presumably by both the TBP phase modifier and the CMPO or CMP extractants, contributes to solvent loading in the extraction flowsheets. Due to the oxidizing conditions of calcine production and subsequent dissolution procedures, chromium remains in predominately the +6 oxidation state in the dissolved Run \#74 calcine solution used as a surrogate in this work. Feed adjustment with a $\mathrm{Cr}$ reducing agent was desired in order to alleviate extraction from dissolved calcine solutions since $\mathrm{Cr}(\mathrm{III})$ is largely inextractable by the process solvents. Ascorbic acid, ferrous sulfamate, and hydrogen peroxide were each tested as reductants for the reduction of $\mathrm{Cr}(\mathrm{VI})$ to $\mathrm{Cr}(\mathrm{III})$. The use of $30 \% \mathrm{H}_{2} \mathrm{O}_{2}$ was selected for the purposes of this test since small volume additions were sufficient for $\mathrm{Cr}$ reduction, minimizing dilution effects, and reduction of the matrix components or radioactive tracers was unlikely. For implementation in large scale actinide separations flowsheets, the selection of appropriate reducing agents must be further studied. Note that $\mathrm{Cr}$ reduction is unnecessary with SBW as the chromium in this waste is anticipated to be in the inextractable $\mathrm{Cr}(\mathrm{III})$ state. 
Table 4. Summary of experimental attempts to define the baseline flowsheets.

\begin{tabular}{|c|c|c|c|c|}
\hline & \multicolumn{2}{|c|}{ SBW } & \multicolumn{2}{|c|}{ Run \#74 Calcine } \\
\hline Property & TRUEX & CMP & TRUEX & CMP \\
\hline $\begin{array}{l}\text { Solvent } \\
\text { Composition }\end{array}$ & $\begin{array}{l}0.2 \mathrm{M} \text { CMPO, } 1.4 \underline{\mathrm{M}} \\
\text { TBP in dodecane } \\
0.2 \mathrm{M} \text { CMPO, } 1.4 \mathrm{M} \\
\text { TBP in Isopar } \mathrm{L}^{\otimes}\end{array}$ & $\begin{array}{l}0.75 \underline{M} \text { CMP, } 1.0 \mathrm{M} \\
\text { TBP in Isopar } L^{\otimes} \\
0.5 \mathrm{M} \text { CMP, } 1.0 \mathrm{M} \\
\text { TBP in Isopar } L^{\otimes} / \checkmark\end{array}$ & $\begin{array}{l}0.2 \mathrm{M} \text { CMPO, } 1.4 \mathrm{M} \\
\text { TBP in dodecane } \\
0.2 \mathrm{M} \text { CMPO, } 1.4 \mathrm{M} \\
\text { TBP in Isopar } \mathrm{L}^{\otimes}\end{array}$ & $\begin{array}{l}0.75 \underline{\mathrm{M}} \text { CMP, } 1.0 \mathrm{M} \\
\text { TBP in Isopar } \mathrm{L}^{\otimes} \\
0.5 \mathrm{M} \text { CMP, } 1.0 \mathrm{M} \\
\text { TBP in Isopar } \mathrm{L}^{\otimes}\end{array}$ \\
\hline $\begin{array}{l}\text { Feed } \\
\text { Adjustment }\end{array}$ & $\begin{array}{l}\text { No need } \\
\text { Identified }\end{array}$ & $\begin{array}{l}\text { No need } \\
\text { Identified }\end{array}$ & $\begin{array}{l}\mathrm{Cr}(\mathrm{VI})-\mathrm{Cr}(\mathrm{III}) \\
\text { Reduction: } \\
\text { 1) Ascorbic Acid } \\
\text { 2) Ferrous Sulfamate } \\
\text { 3) Hydrogen } \\
\text { Peroxider } \\
\mathrm{Zr} \text { Masking: } \\
\text { 1) Ketomalonic Acid } \\
\text { 2) Oxalic Acid } \\
\text { 3) } \mathrm{H}_{2} \mathrm{O} \text { Dilution } \\
\text { 4) } \mathrm{HNO}_{3} \text { Dilution } \\
\text { 5) Ascorbic Acid } \\
\text { 6) Citric Acid } \\
\text { 7) } \mathrm{DTPA} \\
\text { 8) Calcium } \\
\text { 9) } \mathrm{HF} \\
\text { 10) } \mathrm{NH}_{4} \mathrm{~F}\end{array}$ & $\begin{array}{l}\mathrm{Cr}(\mathrm{VI})-\mathrm{Cr}(\mathrm{III}) \\
\text { Reduction: } \\
\text { 1) Ascorbic Acid } \\
\text { 2) Ferrous Sulfamate } \\
\text { 3) Hydrogen } \\
\text { Peroxider }\end{array}$ \\
\hline $\begin{array}{l}\text { Scrub } \\
\text { Solutions }\end{array}$ & $\begin{array}{l}\underline{\mathrm{Zr}}, \mathrm{Fe}, \mathrm{HNO}_{3} \\
\text { 1) } 0.2 \underline{\mathrm{M}} \mathrm{HNO}_{3} \\
\text { 2) } 0.1 \underline{\mathrm{M} N \mathrm{NH}_{4} \mathrm{~F} \text { in }} \\
1 \underline{\mathrm{M}} \mathrm{HNO}_{3} \checkmark \checkmark\end{array}$ & $\begin{array}{l}\text { No need identified: } \\
\left(\mathrm{Am}_{\mathrm{m}} \text { strips at } \sim 1 \underline{\mathrm{M}}\right. \\
\left.\mathrm{HNO}_{3}\right)\end{array}$ & $\begin{array}{ll}\underline{\mathrm{Zr}} & \\
\text { 1) } & 0.2 \mathrm{M} \mathrm{HNO}_{3} \\
\text { 2) } & 0.075 \underline{\mathrm{M}} \mathrm{HNO}_{3} \\
\text { 3) } \mathrm{Al}\left(\mathrm{NO}_{3}\right)_{3} \\
\text { 4) } \mathrm{H}_{2} \mathrm{C}_{2} \mathrm{O}_{4} / \mathrm{HNO}_{3} \\
\text { 5) } \mathrm{HF} \\
\text { 6) } \mathrm{NaF} \\
\text { 7) } 0.1 \underline{\mathrm{M}} \mathrm{NH}_{4} \mathrm{~F} \text { in } \\
\text { 1 } \underline{\mathrm{M}} \mathrm{HNO}_{3} \checkmark \checkmark\end{array}$ & $\begin{array}{l}\underline{\mathrm{Zr}} \\
\text { 1) } 0.1 \underline{\mathrm{M} N \mathrm{NH}_{4} \mathrm{~F} \text { in }} \\
1 \underline{\mathrm{M}} \mathrm{HNO}_{3} \\
\text { 2) } 0.05 \mathrm{M} \mathrm{H}_{2} \mathrm{C}_{2} \mathrm{O}_{4} \\
\text { in } 3 \underline{\mathrm{M}} \mathrm{HNO}_{3} / \checkmark\end{array}$ \\
\hline $\begin{array}{l}\text { Strip } \\
\text { Solutions }\end{array}$ & $\begin{array}{l}\text { 1) } \mathrm{Na}_{2} \mathrm{CO}_{3} \\
\text { 2) } \mathrm{H}_{2} \mathrm{C}_{2} \mathrm{O}_{4} \\
\text { 3) } \mathrm{THF}-\mathrm{TCA} \\
\text { 4) HEDPA }\end{array}$ & $\begin{array}{l}\text { 1) } \mathrm{Na}_{2} \mathrm{CO}_{3} \\
\text { 2) } \mathrm{H}_{2} \mathrm{C}_{2} \mathrm{O}_{4} \\
\text { 3) } \mathrm{HEDPA}\end{array}$ & $\begin{array}{l}\text { 1) } \mathrm{H}_{2} \mathrm{C}_{2} \mathrm{O}_{4} \\
\text { 2) THF-TCA } \\
\text { 3) HEDPA }\end{array}$ & $\begin{array}{l}\text { 1) } \mathrm{H}_{2} \mathrm{C}_{2} \mathrm{O}_{4} \\
\text { 2) HEDPA }\end{array}$ \\
\hline $\begin{array}{l}\text { Mercury } \\
\text { Strips }\end{array}$ & $\begin{array}{l}\text { 1) } 5 \mathrm{M} \mathrm{HNO}_{3} \\
\text { 2) } 0.25 \underline{\mathrm{M} \mathrm{Na}} \mathrm{CO}_{3} \\
\text { \{Either will work\} }\end{array}$ & $\begin{array}{l}\text { 1) } 8 \mathrm{M} \mathrm{HNO}_{3} \\
\text { 2) } 0.25 \mathrm{M} \mathrm{Na} \mathrm{CO}_{3} \\
\text { \{Both ineffective\} }\end{array}$ & $\begin{array}{l}\text { Negligable } \mathrm{Hg} \text { in } \\
\text { calcines }\end{array}$ & $\begin{array}{l}\text { Negligable } \mathrm{Hg} \text { in } \\
\text { calcines }\end{array}$ \\
\hline
\end{tabular}

Selected for subsequent flowsheet testing. 
Initial experiments with the dissolved Run \#74 calcine indicated the TRUEX solvent is virtually loaded with $\mathrm{Zr}$ after several contacts with this feed. This is due to the high affinity of the TRUEX solvent to extract Zr. Under conditions of solvent loading, the distributions for the actinides and other extracted metals are substantially decreased during extraction contacts with the high $\mathrm{Zr}$ containing feeds. The many efforts to mask the extraction of $\mathrm{Zr}$ and consequently increase actinide distributions are documented in Table 4. A serious problem encountered with use of masking agents was precipitate formation in the feed at even very dilute masking agent concentrations, typically greater than about $0.01 \mathrm{M}$. At the dilute concentrations of masking reagents necessary to prevent precipitation, effective decreases in $D_{Z r}$ or increases in $D_{A m}$ for the extraction of the respective species were not observed. It is possible to add $\mathrm{NH}_{4} \mathrm{~F}$ to the Run \#74 calcine solution up to a concentration of $\sim 0.2 \mathrm{M} \mathrm{NH} \mathrm{NH}_{4} \mathrm{Fithout} \mathrm{precipitate} \mathrm{formation.} \mathrm{Increasing}$ the fluoride concentration to $0.25 \mathrm{M} \mathrm{NH}_{4} \mathrm{~F}$ results in the formation of precipitate, presumably $\mathrm{CaF}_{2}$, in the dissolved calcine feed. However, using $0.2 \mathrm{M}$ fluoride in the Run \#74 feed is a possible method to substantially decrease the amount of $\mathrm{Zr}$ extracted, prevent solvent loading, and increase the distribution of the actinides in the extraction contacts. Further testing of $\mathrm{Zr}$ masking with fluoride will be examined in continuing development efforts.

A great deal of work also went into determination of an appropriate, selective $\mathrm{Zr}$ scrubbing reagent from TRUEX solvent contacted with dissolved calcine feeds. The use of 0.1 $\underline{\mathrm{M} \mathrm{NH}} \mathrm{F}_{4}$ in $1 \mathrm{M} \mathrm{HNO}_{3}$ was identified for this purpose. It was also determined that the key reagent was the fluoride, and $\mathrm{NaF}$ or $\mathrm{HF}$ would work equally well under identical conditions. The use of fluoride scrubbing was subsequently carried over to the TRUEX flowsheet with SBW with similar effectiveness for $\mathrm{Zr}$ scrubbing. Note that one potential method of introducing fluoride into the feed stream and enhance $\mathrm{Zr}$ masking as indicated above is simply to increase the $\mathrm{NH}_{4} \mathrm{~F}$ concentration in the scrub solution since this scrub would ultimately combine with the feed in a countercurrent process. When applied to the $\mathrm{CMP} /$ calcine system, fluoride scrubbing with $0.1 \mathrm{M} \mathrm{NH}{ }_{4} \mathrm{~F}$ in $3 \mathrm{M} \mathrm{HNO}_{3}$ effectively scrubbed $\mathrm{Zr}$; however, the distributions of americium were quite low in the scrub contacts $\left(\mathrm{D}_{\mathrm{Am}} \sim 2-3\right)$. Consequently, a dilute oxalic acid/high nitric acid solution was selected as the scrub for the CMP/calcine baseline flowsheet.

The goals for actinide partitioning as applied to ICPP wastes include concentration of the actinides without individual element separation and waste minimization. Gross actinide reextraction from the loaded organic solvent would greatly simplify the process flowsheet and help achieve the required goals. Several stripping reagents were tested to determine the possibility of gross actinide back extraction. A solution consisting of 0.01 to $0.04 \underline{\mathrm{M}} 1$-hydroxyethane-1,1diphosphonic acid (HEDPA) in 0.01 to $0.04 \mathrm{M} \mathrm{HNO}_{3}$ has typically proven to be extremely effective at gross actinide stripping from both the TRUEX and CMP solvents.

Mercury, added as a catalyst in aluminum fuel dissolution, was volatilized and scrubbed during the calcination process and recycled to the SBW storage tanks. Consequently, calcines contain minute quantities of mercury. Both the TRUEX and CMP solvents are effective at extracting $\mathrm{Hg}$ from the SBW matrix. Understanding the fate of mercury in the actinide extraction process is an important part of process development in the case of SBW. 


\section{Matrix Components}

$\underline{\text { Nitric Acid }}$

The TRUEX and CMP solvents will extract nitric acid primarily due to the TBP used as a phase modifier in the organic solvents. The acid and nitrate dependencies of extracted metals plays a major role in the extraction, scrubbing, and stripping behavior for each solvent. Figure 2 presents a graphical comparison of the equilibrium concentrations of nitric acid in the aqueous and organic phases for both solvents. These data were generated at the ICPP for pure nitric acid systems. The data indicate acid extraction is nearly coincidental for the two solvents and is amenable to a reasonable linear fit. The similarity of the two solvents with regard to acid extraction is understandable due to the similar TBP concentrations. Assuming a linear fit, the nitric acid distribution ratios are reasonably constant and an average value can be estimated from the data in Figure 2. For the TRUEX solvent, the average nitric acid distribution coefficient is $\mathrm{D}_{\mathrm{HNO}}=0.52$. Similarly, $\mathrm{D}_{\mathrm{HNO} 3}=0.36$ for the $\mathrm{CMP}$ solvent. The slightly greater affinity for nitric acid with the TRUEX solvent is attributed to the higher concentration of TBP (1.4 $\underline{\mathrm{M}})$ as opposed to the CMP solvent $(1.0 \underline{\mathrm{M}})$.

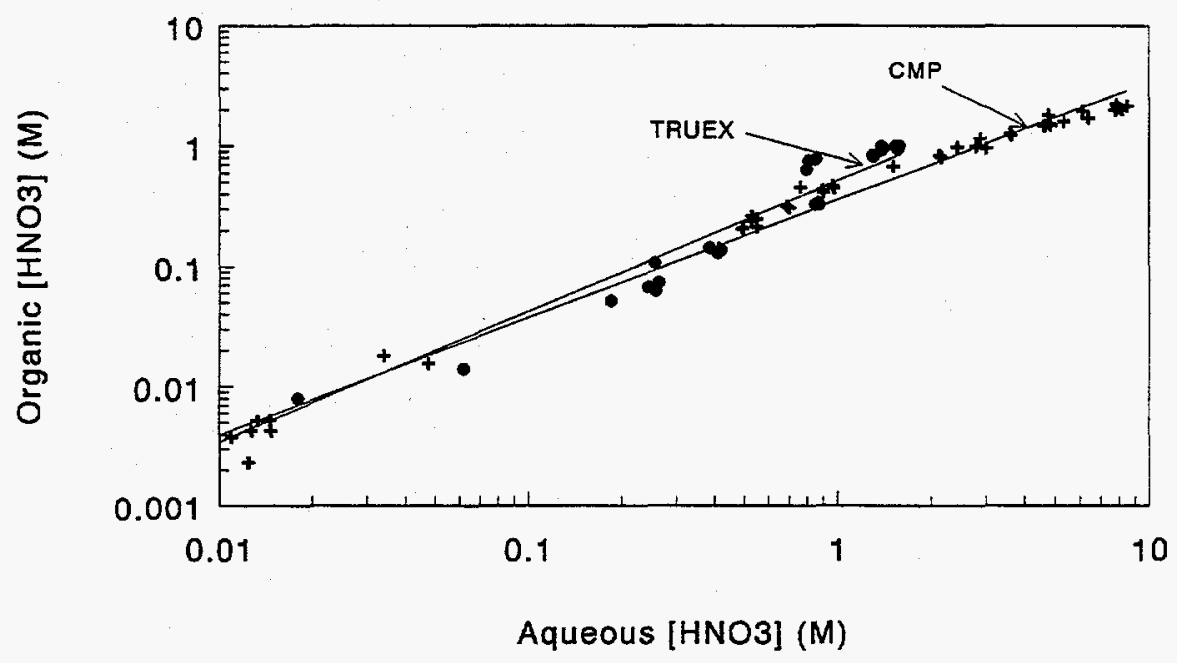

Figure 2. Comparison of nitric acid extraction by the TRUEX and CMP solvents. 


\section{Zirconium}

The zirconium distribution data for the different feeds and solvent systems are listed in Table 5. Note that much of the baseline flowsheet development, particularly for the TRUEX process, was based on the extraction and subsequent scrubbing behavior of $\mathrm{Zr}$ in the two feed solutions. A possible improvement in the baseline TRUEX/Run \#74 calcine flowsheet includes the use of $0.2 \mathrm{M} \mathrm{NH}_{4} \mathrm{~F}$ complexed feed to mask $\mathrm{Zr}$ extraction. Preliminary data indicate the use of $\mathrm{NH}_{4} \mathrm{~F}$ complexed feed in the TRUEX flowsheet slightly decreases the $\mathrm{Zr}$ distribution in the extraction contacts to $\mathrm{D}_{\mathrm{Zr}} \sim 0.5$ and enhances extraction distributions of the actinides. Caution must be used when adding $\mathrm{NH}_{4} \mathrm{~F}$ to the dissolved calcine solution. If the feed is prepared with greater than $0.2 \mathrm{M} \mathrm{NH}_{4} \mathrm{~F}$ an insoluable $\mathrm{CaF}_{2}$ precipitate results [13]. Further work is required with the TRUEX flowsheet before the use of complexed feed is recommended.

The extraction of $\mathrm{Zr}$ from acid solutions has been documented with the TRUEX process solvent $[11,12]$. It is generally postulated that $\mathrm{Zr}$ extraction can be masked using certain complexing agents, such as oxalate. Numerous experiments with $\mathrm{SBW}$ indicate $\mathrm{Zr}$ is quantitatively extracted by the TRUEX solvent. Due to the high concnetration of $\mathrm{Zr}$ in the calcine simulant, the extraction is so pronounced that the the solvent is completely loaded with $\mathrm{Zr}$ and the distribution coefficients of other extracted species are substantially suppressed. The use of dilute ammonium fluoride solution was tested and identified as an effective $\mathrm{Zr}$ scrubbing reagent. A solution of $0.1 \underline{\mathrm{M} \mathrm{NH}} 4 \mathrm{~F}$ in $1 \underline{\mathrm{M}} \mathrm{HNO}_{3}$ quantatively scrubs $\mathrm{Zr}$ from the loaded TRUEX solvent.

Table 5. Comparison of $\mathrm{Zr}$ distributions $\left(\mathrm{D}_{\mathrm{Zr}}\right)$ for simulated wastes using TRUEX and CMP.

\begin{tabular}{|c|c|c|c|c|}
\hline & \multicolumn{2}{|c|}{ SBW } & \multicolumn{2}{|c|}{ Run \#74 Calcine ${ }^{\ddagger}$} \\
\hline Contact & TRUEX & CMP & TRUEX & CMP \\
\hline $\begin{array}{l}\text { E1 } \\
\text { E2 } \\
\text { E3 }\end{array}$ & $\begin{array}{l}23 \\
25 \\
25\end{array}$ & $\begin{array}{l}0.95 \\
1.02 \\
1.05\end{array}$ & $\begin{array}{l}0.83 \\
0.72 \\
0.79\end{array}$ & $\begin{array}{l}0.23 \\
0.22 \\
0.22\end{array}$ \\
\hline Scrubs & $\mathrm{NH}_{4} \mathrm{~F}$ & & $\mathrm{NH}_{4} \mathrm{~F}$ & $\mathrm{H}_{2} \mathrm{C}_{2} \mathrm{O}_{4}$ \\
\hline $\begin{array}{l}\mathrm{Sc} 1 \\
\mathrm{Sc} 2 \\
\mathrm{Sc} 3\end{array}$ & $\begin{array}{l}0.03 \\
0.02 \\
<<1^{\dagger}\end{array}$ & $\begin{array}{c}\text { No } \\
\text { Scrub } \\
\text { Data }\end{array}$ & $\begin{array}{l}0.71 \\
0.17 \\
<<1^{\dagger}\end{array}$ & $\begin{array}{c}0.05 \\
<<1^{\dagger} \\
\mathrm{ND}\end{array}$ \\
\hline Strips & \multicolumn{4}{|c|}{$0.04 \underline{\mathrm{M}} \mathrm{HEDPA}$ in $0.04 \mathrm{M} \mathrm{HNO}_{3}$} \\
\hline $\begin{array}{l}\text { St1 } \\
\text { St2 } \\
\text { St3 } \\
\end{array}$ & $\begin{array}{c}0.006 \\
<<1^{\dagger} \\
\text { ND }\end{array}$ & $\begin{array}{c}<<1^{\dagger} \\
\mathrm{ND} \\
\mathrm{ND}\end{array}$ & $\begin{array}{l}<1^{\dagger} \\
\mathrm{ND} \\
\mathrm{ND}\end{array}$ & $\begin{array}{l}<<1^{\dagger} \\
\mathrm{ND} \\
\mathrm{ND}\end{array}$ \\
\hline
\end{tabular}

The isotope was quantitatively removed from the organic phase for all distributions $<<1$.

Feed reduced with $\mathrm{H}_{2} \mathrm{O}_{2}$

$\mathrm{ND}=$ Not Detected: Isotope was not analytically detected in the organic phase. 
The CMP solvent does not extract $\mathrm{Zr}$ to the same extent as the TRUEX solvent. The necessity to scrub $\mathrm{Zr}$ is uncertain with the SBW. Zirconium scrubbing solutions were tested with the CMP-SBW system to ascertain the effectiveness of scrubbing should this become necessary. Enough $\mathrm{Zr}$ is extracted from the dissolved calcine that $\mathrm{Zr}$ scrubbing is desired to reduce the zirconium concentration in the HLW fraction. Oxalic acid or ammonium fluoride solutions have

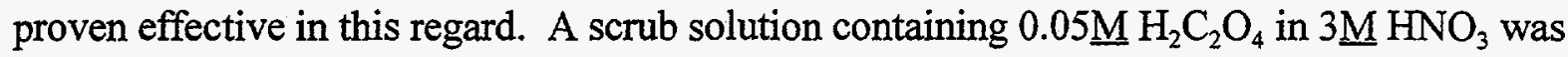
selected for the CMP/Run \#74 calcine flowsheet since $\mathrm{Zr}$ scrubbing was slightly more effective and actinide scrubbing was not as pronounced with this solution relative to the $\mathrm{NH}_{4} \mathrm{~F}$ scrub solution.

\section{Mercury}

The behavior of mercury is of interest only for the treatment of SBW since calcine contains negligible quantities of mercury as a nuance of the calcination process. Mercury is volatilized in the calciner, scrubbed from the off-gas, and recycled to the SBW tanks. The behavior of mercury in the TRUEX process has been extensively examined at the ICPP with regard to SBW. Re-extraction of mercury from the TRUEX solvent requires the use of solutions containing $\geq 5 \mathrm{M} \mathrm{HNO}_{3}$ or sodium carbonate. Potential flowsheet modifications from the selective separation of $\mathrm{Hg}$ from SBW have been examined, and those results are presented elsewhere $[17,18]$.

The extraction behavior of mercury with the CMP solvent is analogous to that of the TRUEX solvent as indicated by the data in Table 6 . However, mercury appears to be more difficult to re-extract from the CMP solvent. It is postulated this behavior is attributed to manufacturing impurities prevalent in CMP. In fact, a proposed CMP purification procedure was developed based on the high affinity of CMP impurities for mercury [19]. A thorough understanding of mercury behavior in the CMP/SBW process will be of key importance for future decisions regarding the use of this separation process. 
Table 6. Comparison of $\mathrm{Hg}$ distributions $\left(\mathrm{D}_{\mathrm{Hg}}\right)$ for simulated SBW with TRUEX and CMP.

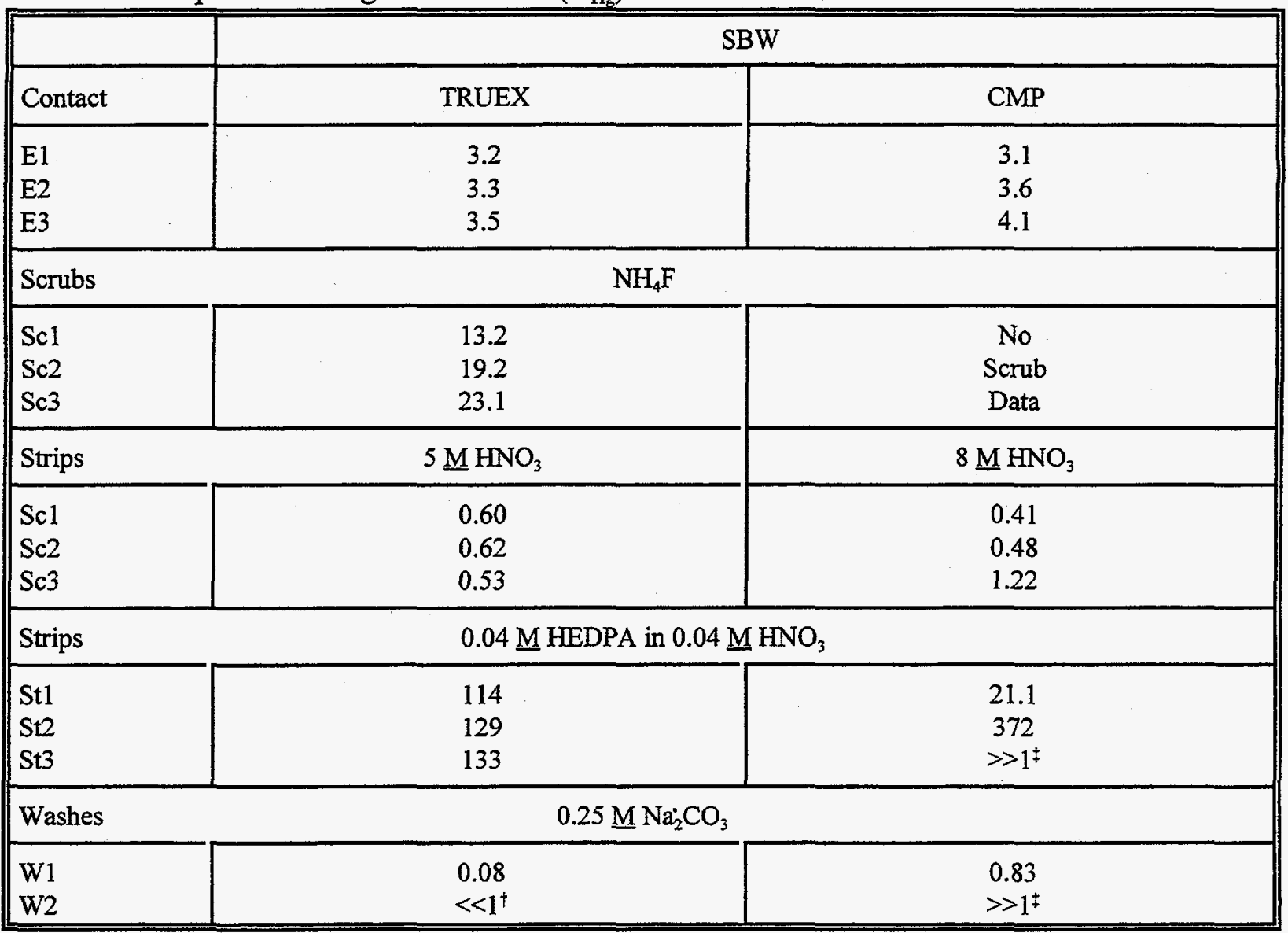

The isotope was quantitatively removed from the organic phase for all distributions $<<1$.

${ }^{\mathrm{t}} \mathrm{Hg}$ was not detectably removed from the organic in this contact.

Iron

Limited data have been obtained for the extraction of iron from the SBW and dissolved calcine solutions with both solvents. For the TRUEX solvent, extraction distributions may be as high as $\mathrm{D}_{\mathrm{Fe}}=1$; however, the extracted iron is readily scrubbed from the TRUEX solvent with the $\mathrm{NH}_{4} \mathrm{~F}$ solution. The extraction of iron appears to be negligible with the CMP solvent $\left(\mathrm{D}_{\mathrm{Fe}}\right.$ $<0.01$ ) for either waste. Consequently, there is currently little concern regarding the fate of $\mathrm{Fe}$ in the CMP process. Further work to elucidate the behavior of Fe for both solvent extraction systems is required; however, this work will be deferred until countercurrent tests are performed in the Centrifugal Contactor Pilot Plant. 


\section{Chromium}

The extraction of chromium from SBW simulant was examined for the TRUEX and CMP solvents. The distribution of $\mathrm{Cr}$ was determined to be negligible $\left(\mathrm{D}_{\mathrm{Cr}} \ll 1\right)$ for both solvents from SBW. This lack of extraction is attributed to the +3 oxidation state of $\mathrm{Cr}$ in the SBW matrix.

Chromium distribution coefficients for both reduced and non-reduced Run \#74 calcine are listed in Table 7. The reduced feed was prepared by the addition of $30 \%$ hydrogen peroxide $\left(\mathrm{H}_{2} \mathrm{O}_{2}\right)$ directly to the calcine solution in the ratio of $\sim 3 \mathrm{~mL} \mathrm{H}_{2} \mathrm{O}_{2} / \mathrm{L}$ calcine solution. Upon addition of the peroxide, the color of the dissolved calcine solution immediately changed from yellow-orange (characteristic of $\mathrm{Cr}(\mathrm{VI})$ ) to blue (typical of $\mathrm{Cr}(\mathrm{III})$ ). It is apparent from the data in Table 6 that the extraction of chromium from the unreduced dissolved Run \#74 calcine solution is pronounced due to the existence of the $\mathrm{Cr}(\mathrm{VI})$ oxidation state in the calcine matrix. The addition of small quantities of reductant virtually eliminates the chromium extraction for both solvent systems. This is particularly beneficial since re-extraction of $\mathrm{Cr}$ from the loaded solvents in the various scrub and strip contacts was quite ineffective. Chromium was not efficiently removed from the organics during the solvent wash contacts with sodium carbonate. Consequently, solvent washing would probably only serve to prevent buildup of $\mathrm{Cr}$ in the organic phase. In the case of the TRUEX solvent, additional solvent loading due to $\mathrm{Cr}$ extraction simply aggravates the problems associated with $\mathrm{Zr}$ extraction.

Note that several reductants, including ferrous sulfamate and ascorbic acid could be used to alter the oxidation state of $\mathrm{Cr}$ in the calcine feed. The use of concentrated hydrogen peroxide was selected for the purposes of this study since the effects of feed dilution was minimal upon addition of $\mathrm{H}_{2} \mathrm{O}_{2}$. Furthermore, reduction of the actinides in the feed is unlikely with the use of peroxide, i.e., $\mathrm{Pu}(\mathrm{VI}) \rightarrow \mathrm{Pu}(\mathrm{IV})$ or $\mathrm{U}(\mathrm{VI}) \rightarrow \mathrm{U}(\mathrm{IV})$. Continued study and optimization of feed reduction is required prior to any large scale implementation. 
Table 7. Comparison of $\mathrm{Cr}$ distributions $\left(\mathrm{D}_{\mathrm{Cr}}\right)$ for reduced and unreduced Run $\# 74$ calcine.

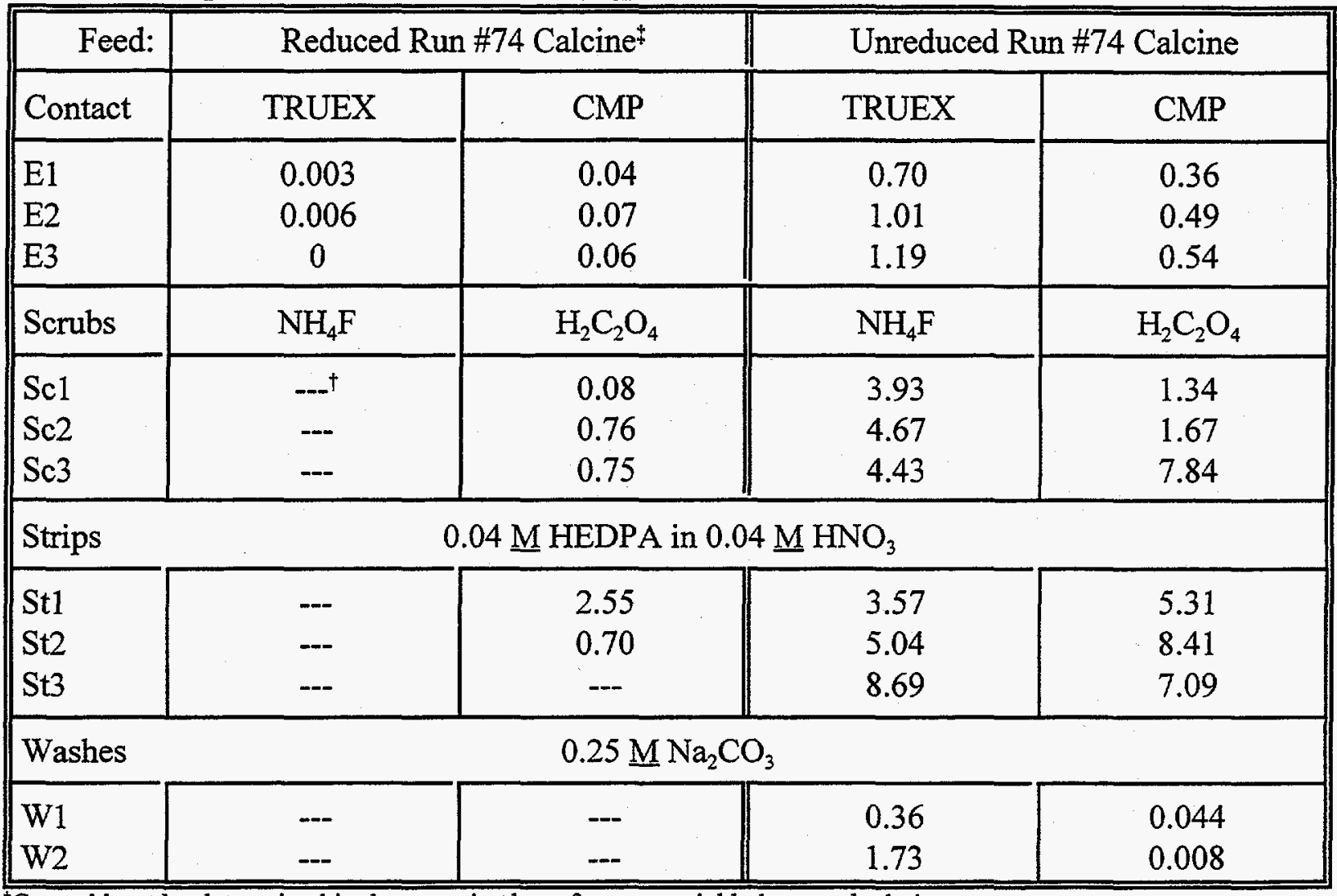

${ }^{\dagger} \mathrm{Cr}$ could not be determined in the organic phase from material balance calculations.

†Feed reduced with $\mathrm{H}_{2} \mathrm{O}_{2}$.

\section{Radionuclides}

\section{Americium}

The behavior of americium is of paramount importance with both extractants for several reasons. First, Am typically exists in the +3 oxidation state in both waste streams. With the exception of elements in the +5 oxidation state (i.e., $\mathrm{Np}(\mathrm{V})$ ), americium is the most difficult actinide to extract from acidic media. Furthermore, Am is prevalent in ICPP wastes at sufficient concentrations that relatively high decontamination must be achieved in order to ensure the LAW raffinate will meet NRC Class A requirements. The ability of the extraction process to suitably achieve necessary americium decontamination virtually guarantees complete removal of the predominate actinides ( $\mathrm{Pu}$ and $\mathrm{U}$ ) and ensure Class $\mathrm{A}$ requirements can be achieved in the LAW.

A comparison of americium distributions are listed in Table 8. In the case of SBW, the extraction of Am is significantly more pronounced with the TRUEX solvent. This behavior is testimony to the stronger extraction capabilities of CMPO. The data indicate Am is more readily and completely stripped from the TRUEX solvent with the HEDPA solution. The higher 
Table 8. Comparison of Am distributions $\left(D_{A m}\right)$ for simulated wastes using TRUEX and CMP.

\begin{tabular}{||l|c|c||c|c||}
\hline Feed: & \multicolumn{2}{|c||}{ SBW } & \multicolumn{2}{c||}{ Run \#74 Calcine $^{\ddagger}$} \\
\hline Contact & TRUEX & CMP & TRUEX & CMP \\
\cline { 2 - 5 } E1 & 29.0 & 11.8 & 4.56 & 7.43 \\
E2 & 31.8 & 11.2 & 2.27 & 7.05 \\
E3 & 32.1 & 10.8 & 1.99 & 7.06 \\
\hline Scrubs & $\mathrm{NH}_{4} \mathrm{~F}$ & & $\mathrm{NH}_{4} \mathrm{~F}$ & $\mathrm{H}_{2} \mathrm{C}_{2} \mathrm{O}_{4}$ \\
\hline Sc1 & 22.8 & $\mathrm{No}$ & 10.2 & 3.1 \\
Sc2 & 19.2 & Scrub & 19.6 & 3.3 \\
Sc3 & 17.4 & Data & 17.8 & 3.3 \\
\hline Strips & \multicolumn{3}{|c|}{$0.04 \mathrm{M}$ HEDPA in $0.04 \mathrm{M} \mathrm{HNO}_{3}$} & \\
\hline St1 & $<<1^{\dagger}$ & 0.41 & 0.12 & 0.32 \\
St2 & $\mathrm{ND}$ & 0.01 & $<<1^{\dagger}$ & 0.01 \\
St3 & $\mathrm{ND}$ & $<<1^{\dagger}$ & $\mathrm{ND}$ & $<<1^{\dagger}$ \\
\hline
\end{tabular}

The isotope was quantitatively removed from the organic phase for all distributions $<<1$.

Feed reduced with $\mathrm{H}_{2} \mathrm{O}_{2}$.

$\mathrm{ND}=$ Not Detected: Isotope was not analytically detected in the organic phase.

Am strip distributions encountered with the CMP solvent are believed to be attributed to manufacturing impurities. Irrespective of these subtle differences, both extraction systems are sufficiently capable of reducing the Am content in SBW to well below the desired levels.

The Am extraction behavior is opposite with the dissolved Run $\# 74$ calcine feed. Americium extraction distributions are higher with CMP than for the TRUEX solvent. This dramatic reduction is attributed solely to loading of the TRUEX solvent, primarily with $\mathrm{Zr}$, during the extraction contacts. Under these conditions, the number of extraction stages would be substantially greater in a flowsheet based on the TRUEX solvent than for CMP to obtain the same levels of Am removal. The Am data indicate the importance of defining a suitable method to prevent $\mathrm{Zr}$ extraction and solvent loading in the TRUEX process.

The data for Run \#74 calcine indicate re-extraction of Am will be more pronounced, but not to unacceptable levels, during the scrub steps in the CMP flowsheet than in the TRUEX process. Consequently, more of the Am will be recycled from the scrub to the extraction section in the CMP flowsheet than with TRUEX. Furthermore, HEDPA stripping is slightly more effective for Am removal from the TRUEX solvent. 
Plutonium

A comparison of plutonium distributions are listed in Table 9. The stock radioisotope used in these extractions was $\mathrm{Pu}-238$. The oxidation state of $\mathrm{Pu}$ in this standard was determined analytically to be partitioned as $70 \% \mathrm{Pu}$ (VI) and $30 \% \mathrm{Pu}$ (IV). It is possible that this ratio of oxidation states was disrupted in the case of dissolved calcine due to the addition of peroxide for $\mathrm{Cr}$ reduction. The distribution data indicate acceptable $\mathrm{Pu}$ extraction and recovery is possible for both feeds with either extraction system. The performance of the TRUEX solvent is slightly better than for CMP, based solely on the distribution data. This behavior is again attributed to the slightly stronger extractant properties of CMPO.

The extraction distributions of Pu by the TRUEX solvent from Run \#74 calcine are substantially lower than expected. This behavior is explained in terms of the solvent loading effects from $\mathrm{Zr}$ in the feed. Development of appropriate methods to prevent $\mathrm{Zr}$ extraction by the TRUEX solvent are anticipated to substantially increase the extraction of Pu from similar feeds. Despite solvent loading, the $\mathrm{Pu}$ distributions are still sufficiently high to allow quantitative removal of $\mathrm{Pu}$ from the dissolved calcine feed.

Table 9. Comparison of $\mathrm{P}_{\mathrm{U}}$ distributions $\left(\mathrm{D}_{\mathrm{Pu}}\right)$ for simulated wastes using TRUEX and CMP.

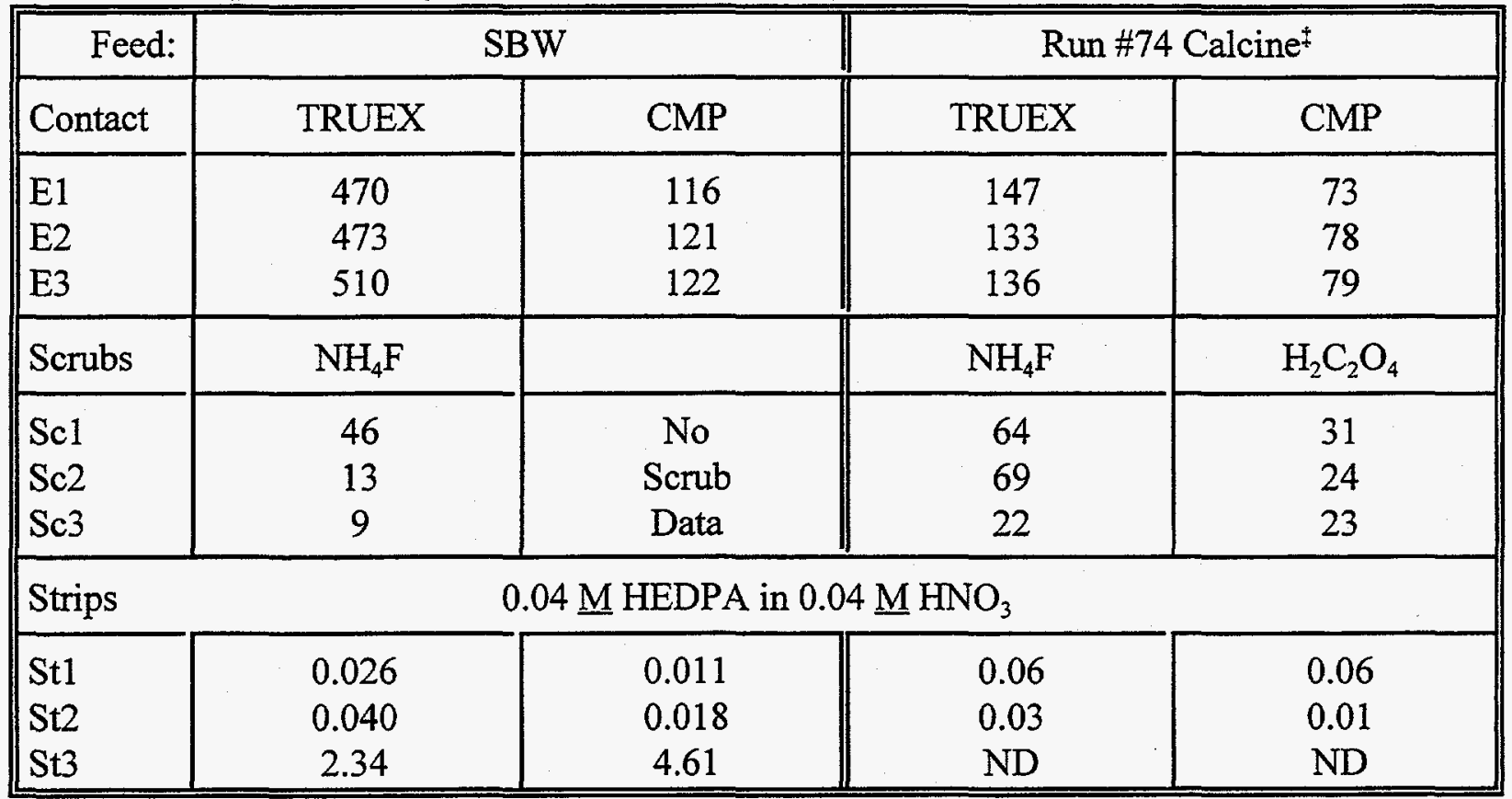

Feed reduced with $\mathrm{H}_{2} \mathrm{O}_{2}$.

$\mathrm{ND}=$ Not Detected: Isotope was not analytically detected in the organic phase. 
Uranium

A comparison of the uranium distribution coefficients are listed in Table 10. The extraction data indicate both extractant systems are quite capable of partitioning $U$ from the respective waste streams. Furthermore, scrub distributions are suitably high and the HEDPA solution is quite effective for $U$ stripping from either extraction system. Comparing the extraction behavior of TRUEX and CMP, the previous trends are observed for uranium and the TRUEX process has a higher affinity for $U$ extraction than does CMP. Enhanced uranium extraction in the TRUEX / Run \#74 calcine process is anticipated, but not required, provided solvent loading effects can be eliminated.

Table 10. Comparison of $\mathrm{U}$ distributions $\left(\mathrm{D}_{\mathrm{U}}\right)$ for simulated wastes using TRUEX and CMP.

\begin{tabular}{|c|c|c|c|c|}
\hline Feed: & \multicolumn{2}{|c|}{ SBW } & \multicolumn{2}{|c|}{ Run \#74 Calcine ${ }^{\ddagger}$} \\
\hline Contact & TRUEX & CMP & TRUEX & CMP \\
\hline $\begin{array}{l}\text { E1 } \\
\text { E2 } \\
\text { E3 } \\
\end{array}$ & $\begin{array}{l}1182 \\
1488 \\
1506 \\
\end{array}$ & $\begin{array}{l}245 \\
260 \\
260 \\
\end{array}$ & $\begin{array}{l}365 \\
401 \\
406\end{array}$ & $\begin{array}{l}143 \\
196 \\
195\end{array}$ \\
\hline Scrubs & $\mathrm{NH}_{4} \mathrm{~F}$ & & $\mathrm{NH}_{4} \mathrm{~F}$ & $\mathrm{H}_{2} \mathrm{C}_{2} \mathrm{O}_{4}$ \\
\hline $\begin{array}{l}\mathrm{Sc1} \\
\mathrm{Sc} 2 \\
\mathrm{Sc} 3\end{array}$ & $\begin{array}{c}259 \\
118 \\
92\end{array}$ & $\begin{array}{c}\text { No } \\
\text { Scrub } \\
\text { Data }\end{array}$ & $\begin{array}{l}277 \\
319 \\
132\end{array}$ & $\begin{array}{l}106 \\
90.5 \\
86.2\end{array}$ \\
\hline \multicolumn{5}{|c|}{$0.04 \underline{\mathrm{M}} \mathrm{HEDPA}$ in $0.04 \underline{\mathrm{M}} \mathrm{HNO}_{3}$} \\
\hline $\begin{array}{l}\text { St1 } \\
\text { St2 } \\
\text { St3 }\end{array}$ & $\begin{array}{c}2.5 \mathrm{E}-04 \\
\mathrm{ND} \\
\mathrm{ND}\end{array}$ & $\begin{array}{c}0.044 \\
2.8 \mathrm{E}-06 \\
\mathrm{ND}\end{array}$ & $\begin{array}{c}0.0425 \\
0.0097 \\
\text { ND }\end{array}$ & $\begin{array}{c}0.04 \\
0.004 \\
\text { ND }\end{array}$ \\
\hline
\end{tabular}

Feed reduced with $\mathrm{H}_{2} \mathrm{O}_{2}$.

$\mathrm{ND}=$ Not Detected: Isotope was not analytically detected in the organic phase. 


\section{Neptunium}

The neptunium distribution coefficients are listed in Table 11. Both solvents are effective for the extraction and recovery of $\mathrm{Np}$ from the wastes under the conditions tested. The TRUEX solvent extracts $\mathrm{Np}$ from the SBW more effectively than the CMP. The scrub and strip distributions are comparable for both solvents and with both waste streams. The scrub solutions do not appreciably re-extract Np from the respective solvent, and HEDPA is very effective for Np stripping from the organics.

The neptunium oxidation state in acidic media is typically associated with $\mathrm{Np}(\mathrm{V})$, and therefore the most difficult actinide to extract. Consequently, the measured extraction distributions from SBW were unexpectedly high. This observation is attributed to the oxidizing nature of the SBW matrix and the potential to disproportionate $\mathrm{Np}(\mathrm{V})$ to a combination of $\mathrm{Np}(\mathrm{IV}), \mathrm{Np}(\mathrm{V})$, and $\mathrm{Np}(\mathrm{VI})$. In the case of Run $\# 74$ calcine, the phenomenally high extraction distributions are easily explained in light of the addition of peroxide to the feed. Peroxide addition, predominately to reduce $\mathrm{Cr}(\mathrm{VI})$ to $\mathrm{Cr}(\mathrm{III})$, also effectively reduces $\mathrm{Np}(\mathrm{V})$ to $\mathrm{Np}(\mathrm{IV})$. It is also possible that the disproportionation of $\mathrm{Np}$ (IV) to $\mathrm{Np}$ (VI) occurs following the initial reduction. The reduction of $\mathrm{Np}$, and the consequential increase in extraction, is a positive result of adjusting the dissolved calcine feed using a reductant such as hydrogen peroxide.

Table 11. Comparison of Np distributions $\left(\mathrm{D}_{\mathrm{Np}}\right)$ for simulated wastes using TRUEX and CMP.

\begin{tabular}{|l|c|c||c|c||}
\hline \multicolumn{1}{|c|}{ Feed: } & \multicolumn{2}{|c||}{ SBW } & \multicolumn{2}{c|}{ Run \#74 Calcine $^{\ddagger}$} \\
\hline Contact & TRUEX & CMP & TRUEX & CMP \\
\cline { 2 - 5 } E1 & 5.6 & 1.2 & $>74$ & $>55$ \\
E2 & 6.7 & 1.4 & $>132$ & $>99$ \\
E3 & 9.1 & 1.4 & $>200$ & 58 \\
\hline Scrubs & $\mathrm{NH}_{4} \mathrm{~F}$ & & $\mathrm{NH}_{4} \mathrm{~F}$ & $\mathrm{H}_{2} \mathrm{C}_{2} \mathrm{O}_{4}$ \\
\hline Sc1 & 8.6 & $\mathrm{No}$ & 113 & 77.2 \\
Sc2 & 7.8 & $\mathrm{Scrub}$ & 148 & 58.5 \\
Sc3 & 5.3 & Data & 112 & 32.7 \\
\hline Strips & \multicolumn{3}{|c|}{$0.04 \mathrm{M}$ HEDPA in $0.04 \mathrm{M} \mathrm{HNO}_{3}$} & \\
\hline St1 & 0.01 & 0.01 & 0.18 & 0.05 \\
St2 & $<<1^{\dagger}$ & $<<1^{\dagger}$ & 0.05 & $<<1^{\dagger}$ \\
St3 & $\mathrm{ND}$ & $\mathrm{ND}$ & $<<1^{\dagger}$ & $\mathrm{ND}$ \\
\hline
\end{tabular}

The isotope was quantitatively removed from the organic phase for all distributions $<<1$. tFeed reduced with $\mathrm{H}_{2} \mathrm{O}_{2}$.

$\mathrm{ND}=$ Not Detected: Isotope was not analytically detected in the organic phase. 
Technetium

Distribution data for technetium are listed in Table 12. It is important to note that the Tc concentrations in ICPP wastes are anticipated to be below NRC Class A LLW requirements as established in 10CFR 61.55. Technetium removal is of concern due to its mobility, as pertechnate, $\mathrm{TcO}_{4}^{-}$, in the environment. It is therefore advantageous to be able to fractionate $\mathrm{Tc}$ from the wastes. Neither solvent is particular effective at extracting Tc, with the TRUEX solvent indicating the most promise. It may be possible to tailor flowsheets to the removal of at least some Tc from the wastes with either solvent. The real issue is the re-extraction of Tc from the organic phase since neither the scrub solutions nor the HEDPA strip solution will effectively re-

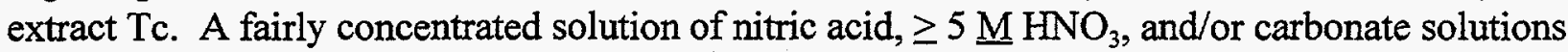
may be used to strip Tc from the organic. This may prove advantageous since a selective Tc partitioning scheme is possible; however, the resulting flowsheet may be more complicated.

Table 12. Comparison of $T c$ distributions $\left(\mathrm{D}_{\mathrm{Tc}}\right)$ for simulated wastes using TRUEX and CMP.

\begin{tabular}{|c|c|c|c|c|}
\hline & \multicolumn{2}{|c|}{ SBW } & \multicolumn{2}{|c|}{ Run \#74 Calcine } \\
\hline Contact & TRUEX & CMP & TRUEX & CMP \\
\hline $\begin{array}{l}\text { E1 } \\
\text { E2 } \\
\text { E3 }\end{array}$ & $\begin{array}{l}1.0 \\
1.0 \\
1.0\end{array}$ & $\begin{array}{l}0.50 \\
0.49 \\
0.50\end{array}$ & $\begin{array}{l}3.03 \\
3.12 \\
3.13\end{array}$ & $\begin{array}{l}0.72 \\
0.73 \\
0.72\end{array}$ \\
\hline Scrubs & $\mathrm{NH}_{4} \mathrm{~F}$ & & $\mathrm{NH}_{4} \mathrm{~F}$ & $\mathrm{H}_{2} \mathrm{C}_{2} \mathrm{O}_{4}$ \\
\hline $\begin{array}{l}\mathrm{Sc} 1 \\
\mathrm{Sc} 2 \\
\mathrm{Sc} 3\end{array}$ & $\begin{array}{l}3.4 \\
4.7 \\
4.7\end{array}$ & $\begin{array}{l}\text { No } \\
\text { Scrub } \\
\text { Data }\end{array}$ & $\begin{array}{l}5.5 \\
8.6 \\
9.3\end{array}$ & $\begin{array}{l}1.8 \\
2.1 \\
2.2\end{array}$ \\
\hline \multicolumn{2}{|c|}{ Technetium Scrubs } & \multicolumn{2}{|c|}{$5 \underline{\mathrm{M}} \mathrm{HNO}_{3}$} & \\
\hline $\begin{array}{l}\mathrm{Sc1} \\
\mathrm{Sc} 2 \\
\mathrm{Sc3}\end{array}$ & $\begin{array}{l}0.95 \\
0.94 \\
0.97\end{array}$ & $\begin{array}{l}0.36 \\
0.38 \\
0.38\end{array}$ & $\begin{array}{l}1.68 \\
1.36 \\
1.14\end{array}$ & $\begin{array}{l}0.31 \\
0.24 \\
0.35\end{array}$ \\
\hline \multicolumn{2}{|l|}{ Strips } & \multicolumn{2}{|c|}{$0.04 \underline{\mathrm{M}} \mathrm{HEDPA}$ in $0.04 \underline{\mathrm{M} \mathrm{HNO}_{3}}$} & \\
\hline $\begin{array}{l}\text { St1 } \\
\text { St2 } \\
\text { St3 }\end{array}$ & $\begin{array}{l}6.8 \\
4.2 \\
2.9\end{array}$ & $\begin{array}{l}15.6 \\
14.1 \\
25.4\end{array}$ & $\begin{array}{c}33.0 \\
81.1 \\
167.1\end{array}$ & $\begin{array}{l}20.3 \\
40.1 \\
58.6\end{array}$ \\
\hline \multicolumn{2}{|l|}{ Washes } & \multicolumn{2}{|c|}{$0.25 \mathrm{M} \mathrm{Na}_{2} \mathrm{CO}_{3}$} & \\
\hline $\begin{array}{l}\text { W1 } \\
\text { W2 }\end{array}$ & $\begin{array}{l}0.16 \\
0.19\end{array}$ & $\begin{array}{l}1.60 \\
2.61\end{array}$ & $\begin{array}{l}0.19 \\
0.21\end{array}$ & $\begin{array}{l}1.11 \\
3.88\end{array}$ \\
\hline
\end{tabular}

Feed reduced with $\mathrm{H}_{2} \mathrm{O}_{2}$ 


\section{Flowsheet Modelling and Comparison}

The distribution coefficients obtained from the laboratory batch contacts were utilized in conjunction with the Generic TRUEX Model (GTM) to develop potential TRUEX and CMP flowsheets for the treatment of SBW and dissolved zirconium calcine. The GTM allows input of user specified distribution coefficients to develop and compare potential flowsheets. The resulting flowsheets are shown in Figures 3 through 6 . The flowsheets for treatment of SBW consisted of five stages of extraction with an $\mathrm{O}: \mathrm{A}=0.33$, four stages of scrub at an $\mathrm{O}: \mathrm{A}=3$

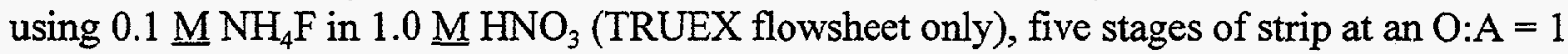
using $0.04 \underline{\mathrm{M}} \mathrm{HEDPA}$ in $0.04 \underline{\mathrm{M}} \mathrm{HNO}_{3}$, two stages of solvent wash at an $\mathrm{O}: \mathrm{A}=1$ using $0.25 \underline{\mathrm{M}}$ $\mathrm{Na}_{2} \mathrm{CO}_{3}$, and one stage of rinse using $0.1 \mathrm{M} \mathrm{HNO}_{3}$ at an $\mathrm{O}: \mathrm{A}=5$. The flowsheets for treatment of dissolved calcine consist of eight stages of extraction ( $\mathrm{O}: \mathrm{A}=0.75)$, four stages of scrub at an

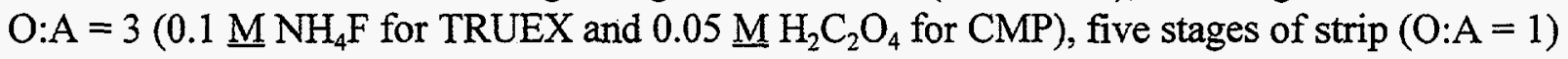
using $0.04 \underline{\mathrm{M}} \mathrm{HEDPA}$ in $0.04 \underline{\mathrm{M}} \mathrm{HNO}_{3}$, two stages of solvent wash (O:A=3) using $0.25 \underline{\mathrm{M}}$ $\mathrm{Na}_{2} \mathrm{CO}_{3}$, and one stage of rinse using $0.1 \underline{\mathrm{M}} \mathrm{HNO}_{3}$ at $\mathrm{O}: \mathrm{A}=5$. The number of stages and $\mathrm{O}: \mathrm{A}$ 's in the various sections were kept constant for a given waste (SBW or dissolved calcine) to form a valid comparison between the two extractants under identical flowsheet conditions. Variations in the number of stages and O:A's between the two waste types were required to obtain the necessary minimum decontaminations due to differences in feed compositions. The average chemical (Table 2) and radiochemical (Table 1) compositions of ICPP SBW and dissolved calcine were used for the feed streams.

As shown in Figures 3 and 4, the TRUEX and CMP flowsheets are both effective at reducing the actinide concentrations in the SBW to below the $10 \mathrm{nCi} / \mathrm{g}$ NRC Class A LLW limit. However, the TRUEX flowsheet reduces the actinide activity to a much lower level than the CMP flowsheet. The $\mathrm{Np}$ activity is only reduced from 3.1 to $1.68 \mathrm{nCi} / \mathrm{g}$ with the $\mathrm{CMP}$ flowsheet. Increasing the number of extraction stages and/or increasing the solvent flowrate, will result in a further reduction of the actinide activity with the CMP flowsheet. With both flowsheets, $\mathrm{Hg}$ is extracted from the SBW and stripped in the $\mathrm{Na}_{2} \mathrm{CO}_{3}$ wash section. Mercury is not as effectively stripped with the CMP flowsheet, resulting in a buildup of $\mathrm{Hg}$ in the CMP solvent to $140 \%$ of the $\mathrm{Hg}$ concentration in the feed. This buildup of $\mathrm{Hg}$ is not anticipated to adversely effect the performance of the CMP flowsheet. Zirconium is partially extracted by the CMP solvent and, since there is not a scrub section, $35 \%$ of the $\mathrm{Zr}$ in the SBW feed exits with the strip product. With the TRUEX flowsheet, $\mathrm{Zr}$ extraction distribution coefficients are $\mathrm{D}_{\mathrm{Zr}} \sim 25$ and scrub distributions are $\mathrm{D}_{\mathrm{Zr}} \sim 0.02$, resulting in a pinch point in the extraction/scrub section. As a result, the $\mathrm{Zr}$ concentration will buildup to unacceptable levels and the majority will exit with the strip product stream (61\%). The large $\mathrm{Zr}$ extraction distribution coefficients obtained with the TRUEX solvent are for batch contacts of SBW and TRUEX solvent. In an actual process, the scrub solution will combine with the SBW feed solution. The $\mathrm{NH}_{4} \mathrm{~F}$ concentration in this combined feed solution is expected to significantly reduce the $\mathrm{Zr}$ extraction distribution coefficients, which will alleviate the pinch point and result in the effective $\mathrm{Zr}$ scrubbing from the solvent. It should be noted that the concentration of $\mathrm{Zr}$ in the SBW feed is small and extraction of this $\mathrm{Zr}$ will have little impact on the composition or volume of the final waste form. 
Technetium is extracted with both of the flowsheets. However, the $\mathrm{Tc}$ in the solvent is not stripped by the $\mathrm{Na}_{2} \mathrm{CO}_{3}$ wash in the CMP flowsheet, resulting in a buildup of Tc in the CMP solvent to $0.01 \underline{\mathrm{M}}$.

As shown in Figures 5 and 6, the TRUEX and CMP flowsheets are both effective in reducing the actinide concentration of the dissolved calcine to below the $10 \mathrm{nCi} / \mathrm{g} \mathrm{NRC}$ Class $\mathrm{A}$ LLW limit. However, the TRUEX flowsheet reduced the Am activity to only $1.0 \mathrm{nCi} / \mathrm{g}$ as compared to $0.0019 \mathrm{nCi} / \mathrm{g}$ for the CMP flowsheet. Americium decontamination could be considerably enhanced by increasing the number of extraction stages and/or the O:A ratio in the extraction section. For the TRUEX and CMP flowsheets, only $1.2 \%$ and $<0.1 \%$ of the $\mathrm{Zr}$, respectively, exited with the strip product. With the TRUEX flowsheet, $90 \%$ of the Tc was extracted from the SBW and effectively stripped in the $\mathrm{Na}_{2} \mathrm{CO}_{3}$ wash section, as compared to $11 \%$ with the CMP flowsheet.

It should be noted that the above flowsheets, with some slight variations, have been tested in continuous, countercurrent mode with simulated wastes in the $5.5 \mathrm{~cm}$ Centrifugal Contactor Pilot Plant at the ICPP and the results are presented elsewhere [20-23]. Each tested flowsheet utilized eight extraction stages, four scrub stages (no scrub for CMP/SBW), four stripping stages, four carbonate wash stages and four acid rinse stages. The number of stages used in the different sections of the flowsheet were based on ease of equipment configuration and not on the actual number of stages necessary to perform the required operation. Organic-to-aqueous phase ratios were extremely close to those used in the computer generated model as stated above. Since the use of radioactive materials is prohibited in the Contactor Pilot Plant, stable Nd was added to the waste simulants as a surrogate for $\mathrm{Am}$.

Both the CMP and TRUEX flowsheets for SBW behaved very similar to the anticipated results from the laboratory data and modelling studies. During the CMP/ SBW contactor experiment, poor hydrodynamic properties of the $0.75 \underline{\mathrm{M}} \mathrm{CMP}$ solvent composition were identified [20]. Due to slow phase disengagement in the carbonate wash section (apparent by flooding) the CMP solvent composition was lowered to $0.5 \underline{\mathrm{M}} \mathrm{CMP}$ and laboratory data reevaluated with this solvent composition. The CMP/ SBW flowsheet was subsequently re-tested in the Centrifugal Contactor Mockup with excellent results [20]. The flowsheet tested in the Contactor Mockup with the TRUEX/ SBW system utilized a $0.07 \mathrm{M} \mathrm{HNO}_{3}$ solution for the scrub [21]. Scrub solution of this composition was selected based on experiments performed prior to the work using $\mathrm{NH}_{4} \mathrm{~F}$ scrubbing. The results indicate that the dilute acid scrub is extremely effective for re-extraction of $\mathrm{Fe}$ and moderately effective for scrubbing $\mathrm{Zr}$ from the loaded organic. Due to the extremely low concentrations of $\mathrm{Zr}$ in SBW, the necessity to scrub $\mathrm{Zr}$ is not of paramount importance (relative to calcine). As indicated by the experimental data and

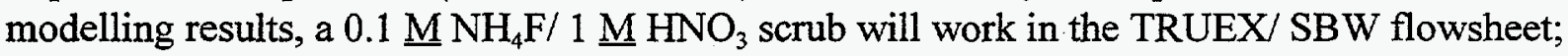
however, the need for its use is not apparent. The data from TRUEX/ SBW contactor experiment were in excellent agreement with laboratory data and the modelling results. Consequently, both the TRUEX and CMP processes have been validated in continuous, countercurrent mode and are both capable of achieving the desired decontamination of the actinides from ICPP SBW. 


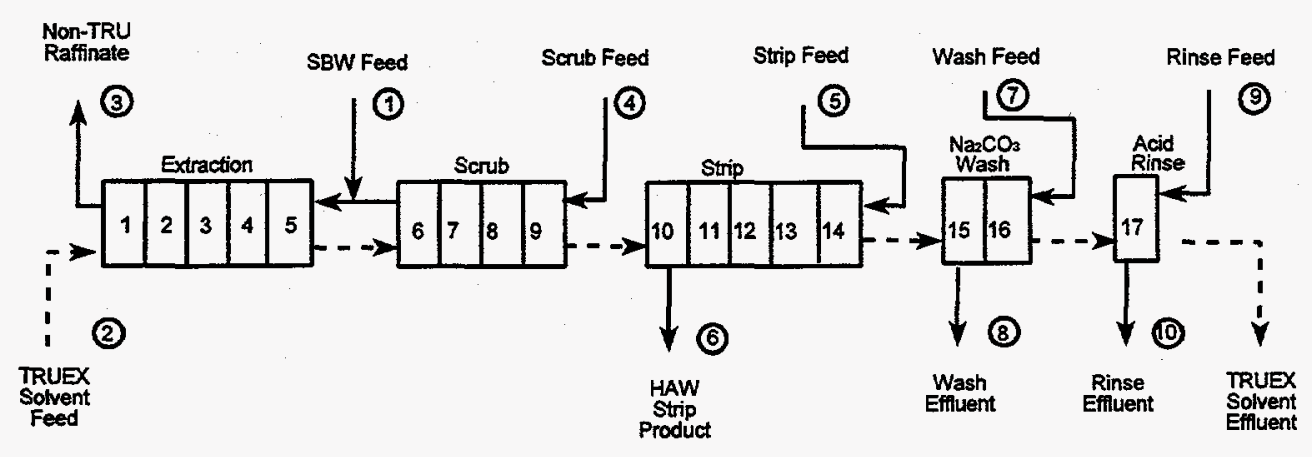

\begin{tabular}{|c|c|c|c|c|c|c|c|c|c|c|}
\hline Comp. & $\begin{array}{c}\text { SBW } \\
\text { Feed } \\
1\end{array}$ & $\begin{array}{c}\text { TRUEX } \\
\text { Solvent } \\
\text { Feed } \\
2\end{array}$ & $\begin{array}{c}\text { Non-TRU } \\
\text { Raff. } \\
3\end{array}$ & $\begin{array}{c}\text { Scrub } \\
\text { Feed } \\
4 \\
4\end{array}$ & $\begin{array}{c}\text { Strip } \\
\text { Feed } \\
5 \\
5\end{array}$ & $\begin{array}{c}\text { Strip } \\
\text { Product } \\
6\end{array}$ & $\begin{array}{c}\text { Wash } \\
\text { Feed } \\
7 \\
\end{array}$ & $\begin{array}{c}\text { Wash } \\
\text { Effluent } \\
8\end{array}$ & $\begin{array}{c}\text { Rinse } \\
\text { Feed } \\
9\end{array}$ & $\begin{array}{c}\text { Rinse } \\
\text { Effluent } \\
10 \\
10\end{array}$ \\
\hline $\mathrm{HNO}_{3}(\mathrm{M})$ & 1.35 & & 1.08 & 1.0 & 0.04 & & & & 0.10 & 0.10 \\
\hline HEDPA (M) & & & & & 0.04 & 0.04 & & & & \\
\hline $\mathrm{NH}_{4} \mathrm{~F}(\underline{\underline{M}})$ & & & & 0.10 & & & & & & \\
\hline $\mathrm{Na}_{2} \mathrm{CO}_{3}(\mathrm{M})$ & & & & & & & 0.25 & 0.25 & & \\
\hline $\mathrm{Zr}(\underline{M})$ & 0.0005 & & $1.75 \mathrm{E}-04$ & & & $8.10 \mathrm{E}-04$ & & & & \\
\hline $\mathrm{Hg}(\underline{M})$ & 0.002 & $7.49 \mathrm{E}-05$ & $2.57 \mathrm{E}-04$ & & & $4.05 \mathrm{E}-05$ & & 0.0045 & & \\
\hline $\mathrm{U}(\mathrm{g} / \mathrm{l})$ & 0.107 & & $3.83 \mathrm{E}-08$ & & & 0.29 & & & & \\
\hline $\mathrm{Am}(\mathrm{nCi} / \mathrm{g})$ & 63.2 & & 0.004 & & & 219 & & & & \\
\hline $\mathrm{Pu}(\mathrm{nCi} / \mathrm{g})$ & 482.9 & & $2.80 \mathrm{E}-04$ & & & 1674 & & & & \\
\hline $\mathrm{Np}(\mathrm{nCi} / \mathrm{g})$ & 3.1 & & 0.024 & & & 10.7 & & & & \\
\hline $\mathrm{Tc}\left(\mathrm{Ci} / \mathrm{m}^{3}\right)$ & 0.04 & 2.22E-04 & 0.025 & & & 0.0058 & & 0.026 & & \\
\hline $\begin{array}{l}\text { Relative } \\
\text { Flow }\end{array}$ & 1.00 & 0.375 & 1.125 & 0.125 & 0.375 & 0.375 & 0.375 & 0.375 & 0.075 & 0.075 \\
\hline
\end{tabular}

Figure 3. TRUEX flowsheet for the treatment of ICPP sodium-bearing waste. 


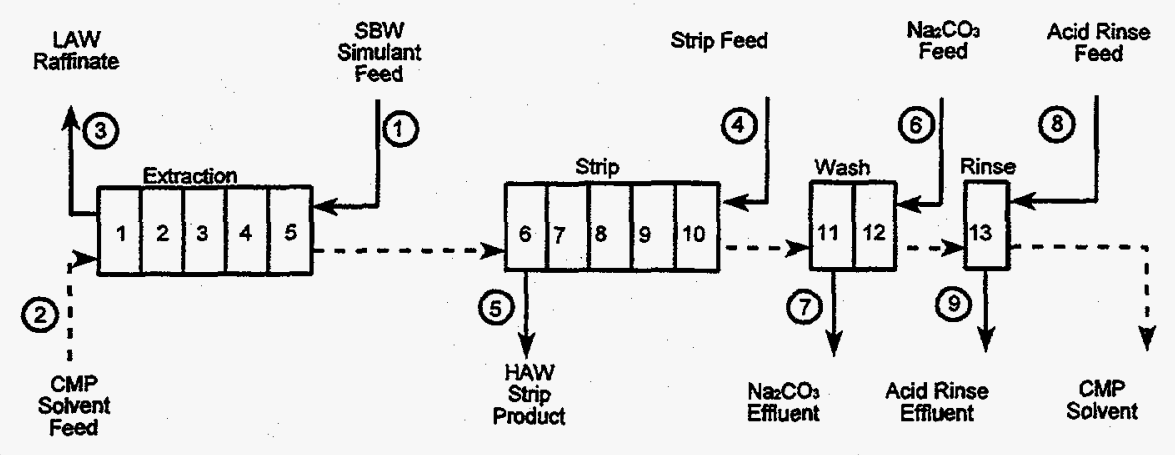

\begin{tabular}{|c|c|c|c|c|c|c|c|c|c|}
\hline Comp. & $\begin{array}{c}\text { SBW } \\
\text { Feed } \\
1\end{array}$ & $\begin{array}{l}\text { CMP } \\
\text { Solvent } \\
\text { Feed } \\
2\end{array}$ & $\begin{array}{c}\text { Non-TRU } \\
\text { Raff. } \\
3\end{array}$ & $\begin{array}{c}\text { Strip } \\
\text { Feed } \\
\vdots \\
4\end{array}$ & $\begin{array}{c}\text { Strip } \\
\text { Product } \\
5\end{array}$ & $\begin{array}{c}\text { Wash } \\
\text { Feed } \\
6\end{array}$ & $\begin{array}{c}\text { Wash } \\
\text { Effluent } \\
7\end{array}$ & $\begin{array}{c}\text { Rinse } \\
\text { Feed } \\
8\end{array}$ & $\begin{array}{c}\text { Rinse } \\
\text { Effluent } \\
9 \\
9\end{array}$ \\
\hline $\mathrm{HNO}_{3}(\mathrm{M})$ & 1.35 & & 0.94 & 0.04 & & & & 0.10 & 0.10 \\
\hline HEDPA (M) & & & & 0.04 & 0.04 & & & & \\
\hline $\mathrm{NH}_{4} \mathrm{~F}(\underline{\underline{M}})$ & & & & & & & & & \\
\hline $\mathrm{Na}_{2} \mathrm{CO}_{3} \mathrm{M}$ & & & & & & 0.25 & 0.25 & & \\
\hline $\mathrm{Zr}(\mathrm{M})$ & 0.0005 & & $3.26 \mathrm{E}-04$ & & $5.23 \mathrm{E}-04$ & & & & \\
\hline $\mathrm{Hg}(\mathrm{M})$ & 0.002 & 0.0028 & $8.84 \mathrm{E}-04$ & & $2.67 \mathrm{E}-04$ & & 0.0031 & & \\
\hline $\mathrm{U}(\mathrm{g} / \mathrm{l})$ & 0.107 & & $1.14 \mathrm{E}-07$ & & 0.42 & & & & \\
\hline $\mathrm{Am}(\mathrm{nCi} / \mathrm{g})$ & 63.2 & & 0.16 & & 246 & & & & \\
\hline $\mathrm{Pu}(\mathrm{nCi} / \mathrm{g})$ & 482.9 & & 0.0014 & & 1884 & & & & \\
\hline $\mathrm{Np}(\mathrm{nCi} / \mathrm{g})$ & 3.1 & & 1.68 & & 5.5 & & & & \\
\hline $\mathrm{Tc}\left(\mathrm{Ci} / \mathrm{m}^{3}\right)$ & 0.04 & 0.010 & 0.037 & & 0.0013 & & 0.0084 & & \\
\hline $\begin{array}{c}\text { Relative } \\
\text { Flow }\end{array}$ & 1.00 & 0.333 & 1.0 & 0.333 & 0.333 & 0.333 & 0.333 & 0.067 & 0.067 \\
\hline
\end{tabular}

Figure 4. CMP flowsheet for the treatment of ICPP sodium-bearing waste. 


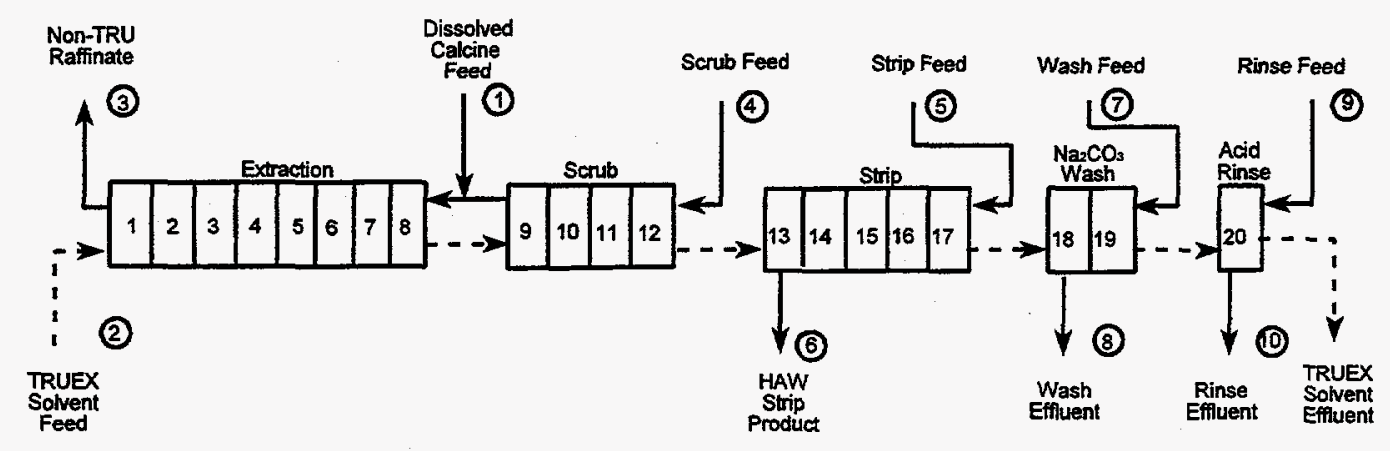

\begin{tabular}{|c|c|c|c|c|c|c|c|c|c|c|}
\hline Comp. & $\begin{array}{c}\text { Dissolved } \\
\text { Calcine } \\
\text { Feed } \\
1\end{array}$ & $\begin{array}{c}\text { TRUEX } \\
\text { Solvent } \\
\text { Feed } \\
2\end{array}$ & $\begin{array}{c}\text { Non-TRU } \\
\text { Raff. } \\
3 \\
3\end{array}$ & $\begin{array}{c}\text { Scrub } \\
\text { Feed } \\
4 \\
4\end{array}$ & $\begin{array}{c}\text { Strip } \\
\text { Feed } \\
5 \\
5\end{array}$ & $\begin{array}{c}\text { Strip } \\
\text { Product } \\
6\end{array}$ & $\begin{array}{c}\text { Wash } \\
\text { Feed } \\
7\end{array}$ & $\begin{array}{c}\text { Wash } \\
\text { Effluent } \\
8\end{array}$ & $\begin{array}{c}\text { Rinse } \\
\text { Feed } \\
9\end{array}$ & $\begin{array}{c}\text { Rinse } \\
\text { Effluent } \\
10 \\
10\end{array}$ \\
\hline $\mathrm{HNO}_{3}(\mathrm{M})$ & 3.5 & & 2.5 & 1.0 & 0.04 & & & & 0.10 & 0.10 \\
\hline HEDPA (M) & & & & & 0.04 & 0.04 & & & & \\
\hline $\mathrm{NH}_{4} \mathrm{~F}(\underline{\mathrm{M}})$ & & & & 0.10 & & & & & & \\
\hline $\mathrm{Na}_{2} \mathrm{CO}_{3}(\mathrm{M})$ & & & & & & & 0.25 & 0.25 & & \\
\hline $\mathrm{Zr}(\mathrm{M})$ & 0.225 & & 0.17 & & & 0.0027 & & & & \\
\hline $\mathrm{U}(\mathrm{g} / \mathrm{l})$ & 0.0027 & & $1.57 \mathrm{E}-10$ & & & 0.0027 & & & & \\
\hline $\mathrm{Am}(\mathrm{nCi} / \mathrm{g})$ & 100 & & 1.0 & & & 128 & & & & \\
\hline $\mathrm{Pu}(\mathrm{nCi} / \mathrm{g})$ & 1085 & & $4.50 \mathrm{E}-04$ & & & 1412 & & & & \\
\hline $\mathrm{Np}(\mathrm{nCi} / \mathrm{g})$ & 0.44 & & $5.17 \mathrm{E}-07$ & & & 0.57 & & & & \\
\hline $\mathrm{Tc}\left(\mathrm{Ci} / \mathrm{m}^{3}\right)$ & 0.027 & 0.0063 & 0.0021 & & & $8.82 \mathrm{E}-04$ & & 0.07 & & \\
\hline $\begin{array}{c}\text { Relative } \\
\text { Flow }\end{array}$ & 1.00 & 1.00 & 1.33 & 0.33 & 1.00 & 1.00 & 0.33 & 0.33 & 0.20 & 0.20 \\
\hline
\end{tabular}

Figure 5. TRUEX flowsheet for the treatment of ICPP dissolved zirconium calcine. 


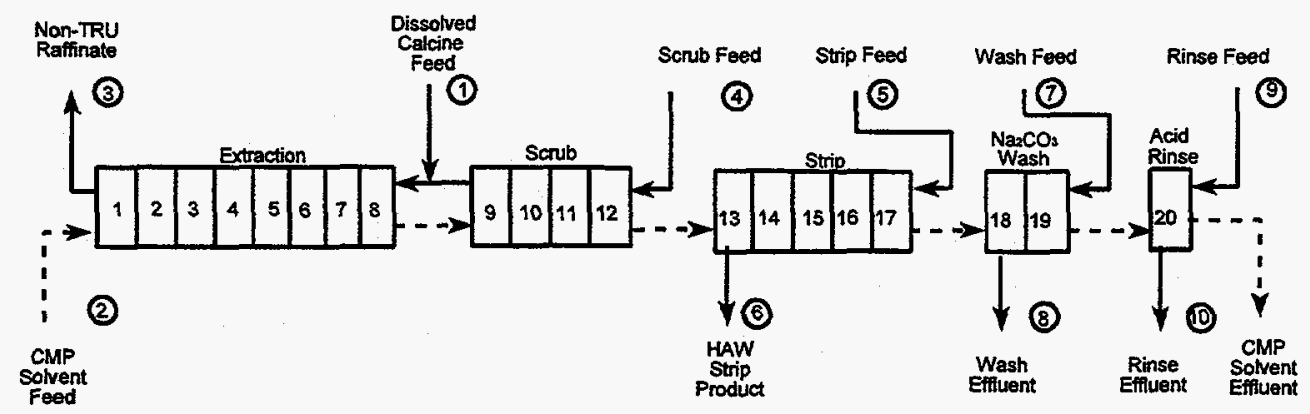

\begin{tabular}{|c|c|c|c|c|c|c|c|c|c|c|}
\hline Comp. & $\begin{array}{c}\text { Dissolved } \\
\text { Calcine } \\
\text { Feed } \\
1\end{array}$ & $\begin{array}{l}\text { CMP } \\
\text { Solvent } \\
\text { Feed } \\
2\end{array}$ & $\begin{array}{c}\begin{array}{c}\text { Non-TRU } \\
\text { Raff. }\end{array} \\
3\end{array}$ & $\begin{array}{c}\text { Scrub } \\
\text { Feed } \\
4 \\
\end{array}$ & $\begin{array}{c}\text { Strip } \\
\text { Feed } \\
5\end{array}$ & $\begin{array}{c}\text { Strip } \\
\text { Product } \\
6\end{array}$ & $\begin{array}{c}\text { Wash } \\
\text { Feed } \\
7 \\
\end{array}$ & $\begin{array}{c}\text { Wash } \\
\text { Effluent } \\
8 \\
8\end{array}$ & $\begin{array}{c}\text { Rinse } \\
\text { Feed } \\
9 \\
9\end{array}$ & $\begin{array}{c}\begin{array}{c}\text { Rinse } \\
\text { Effluent }\end{array} \\
10\end{array}$ \\
\hline $\mathrm{HNO}_{3}(\mathrm{M})$ & 3.5 & & 3.0 & 3.0 & 0.04 & & & & 0.10 & 0.10 \\
\hline HEDPA (M) & & & & & 0.04 & 0.04 & & & & \\
\hline $\mathrm{H}_{2} \mathrm{C}_{2} \mathrm{O}_{4}(\underline{M})$ & & & & 0.05 & & & & & & \\
\hline $\mathrm{Na}_{2} \mathrm{CO}_{3}(\underline{M})$ & & & & & & & 0.25 & 0.25 & & \\
\hline $\mathrm{Zr}(\mathrm{M})$ & 0.225 & & 0.17 & & & $7.49 \mathrm{E}-05$ & & & & \\
\hline $\mathrm{U}(\mathrm{g} / \mathrm{l})$ & 0.0027 & & $2.87 \mathrm{E}-10$ & & & 0.0027 & & & & \\
\hline $\mathrm{Am}(\mathrm{nCi} / \mathrm{g})$ & 100 & & 0.0019 & & & 130 & & & & \\
\hline $\mathrm{Pu}(\mathrm{nCi} / \mathrm{g})$ & 1085 & & 3.83E-04 & & & 1412 & & & & \\
\hline $\mathrm{Np}(\mathrm{nCi} / \mathrm{g})$ & 0.44 & & $1.83 \mathrm{E}-07$ & & & 0.57 & & & & \\
\hline $\operatorname{Tc}\left(\mathrm{Ci} / \mathrm{m}^{3}\right)$ & 0.027 & 0.0097 & 0.018 & & & $6.35 \mathrm{E}-04$ & & 0.0090 & & \\
\hline $\begin{array}{l}\text { Relative } \\
\text { Flow }\end{array}$ & 1.00 & 1.00 & 1.33 & 0.33 & 1.00 & 1.00 & 0.33 & 0.33 & 0.20 & 0.20 \\
\hline
\end{tabular}

Figure 6. CMP flowsheet for the treatment of ICPP dissolved zirconium calcine. 
Experimental verification of the TRUEX and CMP/ dissolved calcine flowsheets were also performed in the Centrifugal Contactor Mockup [22,23]. The Run \#74 feed used in these tests was reduced with $\mathrm{H}_{2} \mathrm{O}_{2}$ to prevent the extraction of chromium as $\mathrm{Cr}(\mathrm{VI})$. The $\mathrm{CMP} /$ calcine flowsheet utilized an oxalic acid scrub and the TRUEX flowsheet was performed with the $\mathrm{NH}_{4} \mathrm{~F}$ scrub solution. Most of the results obtained in these tests were consistent with the laboratory and modelling data. Anomalies were observed in both experiments regarding the behavior of neodymium relative to americium. In the calcine flowsheets, neodymium distributions in the extraction section were substantially suppressed relative to the laboratory data for americium. Furthermore, neodymium distributions decreased in the individual extraction stages as the LLW raffinate end of the cascade was approached. It is currently believed that Nd may not function satisfactorily as an Am surrogate at the higher concentrations of Nd (relative to Am in actual calcine wastes) required to obtain analytical results in the calcine flowsheets due to complexation with the scrub solutions (oxalate and fluoride). This explanation hinges on differences in formation constants of $\mathrm{Nd}_{2}\left(\mathrm{C}_{2} \mathrm{O}_{4}\right)_{3}$ and $\mathrm{Am}_{2}\left(\mathrm{C}_{2} \mathrm{O}_{4}\right)_{3}$ for the CMP process and of $\mathrm{NdF}_{3}$ versus $\mathrm{AmF}_{3}$ in the TRUEX process. The increased complexation of $\mathrm{Nd}$ essentially masks its extraction. It is also possible that the much higher concentrations of $\mathrm{Nd}$, relative to $\mathrm{Am}$ in the laboratory studies, used in the contactor tests may have suppressed distributions due to mass and loading effects. Further experimentation is required to determine the applicability of using $\mathrm{Nd}$ as an Am surrogate in calcine flowsheet development work. Such experimentation will be conducted in conjunction with an evaluation of $\mathrm{Zr}$ behavior and solvent loading in the TRUEX/ calcine process.

The development work conducted to date has indicated the applicability of both extraction systems for the treatment of ICPP wastes. These results will be validated with actual wastes on a continuous, countercurrent mode in equipment similar to that actually anticipated for a full scale process, i.e., centrifugal contactors. Verification of at least the TRUEX flowsheets will be performed in the future with samples of actual SBW in the $2 \mathrm{~cm}$ Centrifugal Contactor Pilot Plant located in the Remote Analytical Laboratory hot cell. 



\section{CONCLUSIONS}

Adequate actinide removal from the SBW can be achieved with either the TRUEX or CMP processes to meet NRC Class A LLW requirements. The TRUEX process is slightly better in light of the presented data due to higher extraction distributions. This advantage is offset by the need for a scrubbing section in the TRUEX process while scrubbing is not necessary with CMP. In this regard, the CMP process flowsheet is somewhat simpler than that for the TRUEX process. Consequently, the size of the separation train is expected to be very similar for actinide decontamination of SBW with both extractants. It is apparent from the flowsheet modelling results that smaller volumes of LLW raffinate and strip product are produced using the CMP flowsheet. This minimization is achieved relative to the TRUEX flowsheet due to the lack of a scrub section and a given O:A in the different sections. A serious drawback of the CMP process as applied to SBW involves the behavior of $\mathrm{Hg}$ and $\mathrm{Tc}$. CMP effectively extracts both $\mathrm{Tc}$ and $\mathrm{Hg}$, but they are not removed from the organic in the strip or wash sections resulting in a buildup of $\mathrm{Hg}$ in the organic phase.

A comparison of the two extractants for actinide partitioning from $\mathrm{Zr}$ calcine types indicates that CMP may be a better choice as the extractant with this feed based solely on the behavior of $\mathrm{Zr}$ and the effects of loading the TRUEX solvent. This $\mathrm{Zr}$ loading effect significantly lowers the extraction of the actinides; in fact, Am decontamination is barely sufficient for the baseline flowsheet. Note that the Am decontamination of the LLW raffinate could be substantially increased by using additional stages or increasing the O:A ratio in the extraction section of the TRUEX flowsheet. Excessive loading of the TRUEX solvent may significantly impact the hydrodynamic and physical properties of the solvent. This could potentially result in decreased equipment efficiencies and/or the formation of undesirable precipitates during countercurrent operation. 



\section{RECOMMENDATIONS}

Recent budget shortfalls and personnel limitations have severely impacted the separations development plans. It is recommended that CMP process development efforts be temporarily reduced or suspended, keeping this process in the background until it is more certain that TRUEX is not applicable. This recommendation is based primarily on the fact that CMP is commercially unavailable, has a much weaker technical maturity, and that the problems encountered with TRUEX can be quickly and satisfactorily resolved.

Baseline flowsheets have been established and tested for both extractant systems with simulated wastes. The SBW flowsheets performed to expectations and the TRUEX/ SBW flowsheet should be verified in the $2 \mathrm{~cm}$ centrifugal pilot plant with actual waste in the near future. This will be the final validation of this flowsheet.

A great deal of work is required to develop flowsheets for $\mathrm{Zr}$ calcine. Available resources should be utilized with primary focus on the development of TRUEX/calcine flowsheets. This would be accomplished by performing laboratory tests to determine suitable or "best" methods for eliminating the problems associated with $\mathrm{Zr}$ extraction. Candidate flowsheets would then be tested in the $5.5 \mathrm{~cm}$ Centrifugal Contactor Pilot Plant with simulated waste. At this point, CMP flowsheet development could be re-established if the problems with the TRUEX process could not be resolved. Finally, pending the identification of an acceptable TRUEX flowsheet, verification and validation would be performed with actual dissolved calcine in the 2 $\mathrm{cm}$ centrifugal contactors. Several potential methods are currently being evaluated to alleviate $\mathrm{Zr}$ loading of the TRUEX solvent. These options, which may also be used simultaneously, include:

1) Optimization of the fluoride and acid concentrations in the scrub solution. Additional fluoride in the scrub, when combined with the feed, could minimize $\mathrm{Zr}$ extraction by fluoride complexing. A decrease in the acid concentration in the scrub solution may be possible to enhance $\mathrm{Zr}$ re-extraction in the scrub section. This combination is expected to prevent the precipitation of $\mathrm{Zr}\left(\mathrm{PO}_{4}\right)_{2}$, which was encountered in the stripping section during the TRUEX/ dissolved calcine flowsheet tests. Ancillary considerations with altering the scrub solution composition includes the behavior of $\mathrm{Pu}$, which is known to readily complex with fluoride, and precipitation of $\mathrm{CaF}$ from the feed solution at higher fluoride concentrations.

2) Increasing the CMPO concentration in the TRUEX solvent. The dissolved calcine contains approximately $0.23 \mathrm{M} \mathrm{Zr}$ (some of which is complexed by the fluoride present). The current TRUEX solvent incorporates $0.2 \mathrm{M}$ CMPO and recent evidence suggests 2 moles of CMPO are consumed per mole of $\mathrm{Zr}$ extracted. Consequently, the available CMPO is essentially tied up by extracted $\mathrm{Zr}$ (this is solvent loading). It may be possible to increase the CMPO concentration to $0.25 \underline{\mathrm{M}}$ or even $0.30 \underline{\mathrm{M}}$ to increase the available extractant in the solvent. Care must be exercised to insure the hydrodynamic properties of the TRUEX solvent do not deteriorate at increased CMPO concentration. 
3) Dilution of the feed with water or acid. Zirconium concentrations in the feed could be reduced by physical dilution with either acid or water. This option is the least appealing from a waste minimization standpoint since the volume of the LLW fraction would be increased.

It is extremely important to mention that the CMP extractant is no longer available commercially. Furthermore, CMP purity requirements are not well defined and the ability to produce mass quantities of this material at sufficient purity is uncertain. Chemical purity is anticipated to be of particular importance in the case of mercury behavior, relevant primarily for treatment of the SBW. Another pertinent issue associated with the CMP system is the lag in technical maturity compared with the TRUEX process. Much study has been devoted to the behavior of TRUEX under a wide variety of conditions and for numerous waste streams. The lack of technical maturity will certainly impede CMP process development since key fundamental information, such as hydrolytic and radiolytic stability, optimal solvent composition, etc., is not readily available. 


\section{REFERENCES}

[1] Berreth, J. R., "Inventories and Properties of ICPP Calcined High-Level Waste", WINCO-1050, February 1988.

[2] Murphy, J. A., et.al., "ICPP Radioactive Liquid and Calcine Waste Technologies Evaluation Final Report and Recommendation", INEL-94/0119, April 1995.

[3] Olson, A. L., et.al., "Evaluation and Selection of Aqueous-Based Technologies for Partitioning Radionuclides From ICPP Calcine", WINCO-1171, February 1993.

[4] Horwitz, E. P., et.al., Sol. Extr. \& Ion Exch., $\underline{3}(1 \& 2), 75(1985)$.

[5] Sidall, T. H., Journal of Inorg. \& Nucl. Chem., 26(11), 1991(1964).

[6] Mclsaac, L. D., et. al., "Actinide Removal From ICPP Wastes", ICP-1080, August 1975.

[7] McIsaac, L. D., et. al., "Study of Bidentate Compunds for Separation of Actinides from Commercial LWR Reprocessing Waste", ICP-1180, February 1979.

[8] Maxey, H. R., et. al., "Removal of Actinides from ICPP Fuel Reprocessing Wastew: Engineering Studies Terminal Report", ENICO-1057, September 1980.

[9] Marsh, S. F., et. al., "Comparative Evaluation of DHDECMP and CMPO as Extractants for Recovering Actinides from Nitric Acid Waste Streams", LA-11191, Feb. 1988.

[10] Lumetta, G. J., et. al., Sol. Extr. \& Ion Exch., 12(5), 967(1994).

[11] Herbst, R. S., et. al., "TRUEX Partitioning From Radioactive ICPP Sodium Bearing Waste", INEL-95/0224, March 1995.

[12] Brewer, K. N., et. al., "Actinide Partitioning From Actual ICPP Dissolved Zirconium Calcine Using The TRUEX Solvent", INEL-95/0225, May 1995.

[13] Herbst, et. al.,"Experimental Results: Pilot Plant Calcine Dissolution and Liquid Feed Stability", INEL-95/0097, February 1995.

[14] Brewer, K. N., et. al., "Dissolution of Two NWCF Calcines: Extent of Dissolution and Characterization of Undissolved Solids", INEL-95/0098, February 1995.

[15] Brewer, K. N., et. al., "CMPO Purity Tests in the TRUEX Solvent Using Americium-241", WINCO-1177, December 1993.

[16] Chiarzia, R., Horwitz, E. P., Sol. Extr.\& Ion Exch., $\underline{8}(6), 907(1990)$.

[17] Herbst, R. S., et. al., Sol. Extr. \& Ion Exch., 13(3), 431(1995).

[18] Brewer, K. N., et. al., Sol. Extr. \& Ion Exch., 13(3), 447(1995).

[19] Krupa, J. F., et. al., "Actinide Partitioning from ICPP Waste: An Investigation of Methods to Eliminate Mercury Interference", ICP-1181, March 1979.

[20] Law, J. D., et. al., "CMP Flowsheet Development for the Separation of Actinides from ICPP Sodium-Bearing Waste Using Centrifugal Contactors", INEL-95/0414, Aug. 1995.

[21] Law, J. D., et. al., "TRUEX Flowsheet Development as Applied to ICPP Sodium-Bearing Waste Using Centrifugal Contactors", INEL-95/0130, February 1995.

[22] Law, J. D., et. al., "CMP Flowsheet Development for the Separation of Actinides from Dissolved ICPP Calcine Using Centrifugal Contactors", INEL-95/0582, November 1995.

[23] Law, J. D., et. al., "TRUEX Flowsheet Development as Applied to Dissolved ICPP Calcine Using Centrifugal Contactors", In Press, 1996.

[24] Todd, T. A. , et. al., "The Extraction of Rare Earth Elements From ICPP Sodium-Bearing Waste and Dissolved Zirconium Calcine by CMP and TRUEX Solvents", INEL-95/0642, November 1995.

[25] Brewer, K. N., et. al., "Actinide Partitioning Using CMP and Dissolved Zirconium Calcine", INEL-96/0021, January 1996.

[26] Herbst, R. S., et. al., "Actinide Extraction of ICPP Sodium Bearing Waste With 0.75 M DHDECMP/TBP In Isopar L ", INEL-96/0036, January 1996. 